\title{
A Suit for the Physical Training: Application and the Value of Innovation
}

\author{
Miroslav Dodig \\ University of Rijeka, Rijeka, Croatia \\ Email address: \\ dodig@pfri.hr \\ To cite this article: \\ Miroslav Dodig. A Suit for the Physical Training: Application and the Value of Innovation. American Journal of Sports Science. \\ Vol. 7, No. 2, 2019, pp. 34-52. doi: 10.11648/j.ajss.20190702.11
}

Received: March 17, 2019; Accepted: April 26, 2019; Published: May 23, 2019

\begin{abstract}
By recognizing the sequential body configuration and time shifts, it is possible to calculate the dynamic moment of inertia. Body, arm, and leg models were proposed in which possible configurations and influential mass distribution sizes were studied. Described is the choice of optimal models for modeling dynamic moments of inertia which are represented as the best approximation for the dynamic moment of inertia in a dynamic sense. Dynamic and physiological parameters (aerobic, aerobic-anaerobic and anaerobic stimuli) are load indexes based on the geometric progression of the metabolic processes (aerobic - index 3, aerobic-anaerobic - index 6 and anaerobic - index 12). For this purpose, the QBASIC program was used to calculate the weight gain for individual segments according to load indexes (index - 3, 6 or 12). A weight gain calculation program for individual segments according to load indexes of male and female bodies was used to calculate the mass, volume and thickness of silicone with and without the addition of lead balls or lead dust. The training process suit represents a threelayer suit where the suit layers are as follows: the first layer (Lycra) which adheres directly to the skin and which must have an elasticity factor that will satisfy the required flexibility and moisture absorption; the second layer (Silicone) the weight of which is proportionately distributed so that the weight of each segment of the second layer corresponding to each individual body segment is equal to the weight gain for that particular body segment; the third layer (Lycra) which is an outer layer and which is watertight but at the same time passes moisture outwards and is elastic. On this basis, a three-layer suit was made with proportionally distributed loads per individual body segments, which ensures proportional load of the segments and the whole body. Thus applied stimuli provide an even impact on the development of the musculoskeletal nervous system in the direction of the development of motor potentials at a high correlation level in the coordination of body motion in the chosen activity. Application, testing and measurement of the suit performance in certain sport movements (walking, running, pedaling, rowing, volleyball and basketball) were carried out using the POLAR measuring instrument and heart beat frequencies depending on intensity of the load were obtained. Based on the information obtained, the Training Process Suit can be used for sports training, recreational activities and for medical purposes when carrying out physical therapy.
\end{abstract}

Keywords: Suit, Model, Modeling, QBASIC, Display, Application, Training, Results

\section{Introduction}

Starting from the fact that there was a need for a training process suit which would, with its characteristics, above all equally distributed weight and therefore uniformly distributed additional load on the person wearing the suit, aid in the development of functional and motor properties of the body. Such a suit would be useful for both professional and recreational athletes, to maximize and proportionally take advantage of the load that the training suit adds to the training itself. Furthermore, there was a need for a suit which is practical and comfortable to wear for the person training in it since training sessions usually last from 45 to 90 minutes. Also, such a suit would reduce the length of the training session due to the increased intensity and increase the development of functional and motor skills by perfecting the coordination of motion for the development of superior motor skills for top achievements.

To date, research has been conducted on a few training suits, which mainly relate to the dynamics and propulsion of 
the body in a specific fluid and sections for thermoregulation of larger muscle groups. In the state of the art, solutions for the physical training process with the objective of the development of functional and motoric abilities of the body do not exist that are based on the proportional application of force on either parts of or the entire body.

Patent no. US5659898 refers to a training suit that is constructed of two layers that are made of an elastic fabric, between which a number of flexible weights arranged lengthwise are located, wherein the mentioned weights are situated parallel to one another throughout the entire length of the suit. The flexible weights are made of polyurethane, in which metal fibers have been added in order to gain on weight. In this manner, a suit that is of the same weight on each individual potion of the suit has been achieved, which consequently, does not take into account the proportional application of force on each segment of the body. Due to this, such a suit violates the natural coordination of the movement of the body. Such a suit cannot be functional toward the development of specific motoric abilities and superior body movement techniques due to the infringement of synergic regulations in movement. Likewise, its benefit of use in a direct training process may have negative effects. When executing techniques of a specific body movement, such a suit can negatively influence the synergic regulation of muscular activity and disturb the coordination of movement.

Patent US8256034 refers to a training suit that consist of two layers made of an elastic fabric, between which chambers are located that serve for receiving fluids or inserting elements that can be sponges, chambers or plates filled with gas, chambers filled with liquid, or electronic devices. The invention specifically refers to the heating or cooling of the suit with a liquid that fills the chambers or inserted elements located inside the suit.

Patent application US2004221355 refers to a training suit used for swimming that incorporates exterior pockets in which weights can be inserted. Furthermore, the following patent applications/patents incorporate pockets into a suit, in which weights can be inserted, in order to increase the weight of the suit in particular areas of the suit: US2010319099, GB2462477, WO0226330, US6364851, US5937441, US4384369, US5768706 and US5144694. Such pockets unevenly distribute the weights' weight on the suit and hence, on the exerciser's body and thus do not take account of proportional application of force upon individual segments of the body.

It is important to emphasize that the above-mentioned suits do not sufficiently use the principles of anatomy, physiology, kinesiology and biomechanics, and therefore do not aid in achieving optimal performance during training; a possibility exists that some elements may produce negative effects. With respect to these principles, the human body acts as a multidimensional system that is integrated in the musculoskeletal system. The stated principles constitute a functional unit, whose joint actions result in body movement. The function of the musculoskeletal system is determined by direct (bones, joints, skeletal muscles, deep sensibility motor nerve pathways) and indirect (metabolism, breathing, blood circulation, etc.) elements.

Regulations of the mechanisms of the movements of the human body are focused on the internal and external dynamic processes of the musculoskeletal system. It is known that the musculoskeletal system performs body movements in kinetic chains, which through muscles, joints, bones and nerve innervations in addition to frequent repetition, increase the ability of movement and create movement stereotypes. Therefore, the musculoskeletal structures create motoric programs that are manifested by the body's movement. For the realization of movement, appropriate basic kinetic elements are necessary (time (S), amplitude or distance (m) and resistance $(\mathrm{kg})$ ), which define the type of movement with their configuration and distribution. Based on the kinetic elements, the basic units of measurement of physical motion are obtained: force $(\mathrm{N})$, power $(\mathrm{W})$, velocity $(\mathrm{V})$ and work $(\mathrm{J})$. This principle indicates that it is necessary to respect combinational logic for the development of a specific movement. Assuming that one movement has a constant time and amplitude of movement, then the variability of resistance (weight) is that which affects the covariability and changes the structure of movement. This principle is the basis in the system for the transformation of movement from the initial to final state. A suit that does not have the possibility of manipulating the distribution of proportional weight during its application process cannot significantly contribute to the positive transformation of movement. Contrarily, if the law of harmony is not obeyed, i.e. if body segments in motion are not proportionally exerted, this often leads to the impairment of synergic regulation within the structure, and with considerable consequences. Therefore, in order to produce optimal effects, a suit for the development of physical fitness of the body must take into account the proportional distribution of exertion as well as of the level of proportional distribution of exertion that is necessary to execute the necessary transformations in the body (aerobic, aerobic-anaerobic, anaerobic), which is the objective of this invention.

\section{Model and Modeling of the Dynamic Moment of the Training Process Suit}

The training suit is designed for adjustment of the proportional load per individual body segments or the whole body. On this basis, the movement of the body with proportional load per all body segments is impacted, which significantly affects the synergy functions of the body and does not disturb the coordination of movement, increases the metabolic processes while at the same time raising the functional and motor skills to a higher degree. The transformational changes that occur in the body are in great correlation with certain kinetic structures in the selected sport or activity. Due to the high congruency between the suit and the selected activity, the development of motor and functional characteristics will quickly occur. Such a development will have a significant impact on the development of form and top motion technique, which will 
result in easier achievement of top results in sports, recreational and therapeutic activities. ${ }^{1}$

Starting from the fact that kinetic energy or energy of a body in motion is measured by the action the body can perform by overcoming external forces, before it is brought to idle state. A body with the mass $m$ and velocity $v$ has a kinetic energy of $T=$ $m v^{2} / 2$. It is clear that basic kinetic motion laws are based on mechanical laws. By introducing the basic units of length, time and mass, the basic terms on spatial forms, materiality of the body and the time in which these changes occur are also expressed. In dynamics, force is not a basic element, it is defined by basic physical dimensions (space, mass - time). The definition of force in dynamics was given by Newton (Philosophiae naturalis principia mathematika, London, 1687), in the form of three axioms.

One part of the human body cannot be arbitrarily moved in all directions relative to the rest of the body due to the specific structure of the joint-bone part of the movement apparatus. This same body part cannot be moved by arbitrary muscle strength because the muscle cannot act from just any position. In addition, the agonist muscle potential is not the same in all directions, so a certain body part cannot be started in different directions by force of always the same magnitude. This movable body part moves in a natural environment and is influenced by external forces. In order to find the possibility of starting certain kinetic chains (body parts), a biomechanical analysis of the kinetic structure involving certain kinetic chains must be performed. Complex motion is composed of a series of spatial, timely movements and is determined by the anatomical-mechanical analysis. The anatomicalmechanical motion analysis uses knowledge from anatomy (static and dynamic anatomy) and mechanics of living beings, biomechanics. The dynamic behavior of kinetic chains requires a knowledge of the distribution of its segment masses, and thus the dynamic moments of inertia, which was the main objective of this study. The motion of human body is possible in dynamic and static conditions. To define the dynamic moments of body motion inertia, it is necessary to know the distribution of mass in the segments of certain open and closed kinetic chains. Important contributions to the research of the body's dynamic moment of inertia were given by: Božić, Ž., [1] (1988), Donskij, D. D, Zacijorskih, V. M., [15] (1979), Kaleps, O., Clauser, C. E. et al., [18] (1984), Korenev G. B., [19] (1977), Muftić, O., Krajina, B., [20] (1988), Radoš, N., [21] (1988), Rudan, P., [22] (1978) and Dodig, M., [4-8, 12, 14] (1994, 1998, 2002, 2008, 2016, 2019).

Starting from the fact that the body model is based on a mechanical system with 16 absolutely rigid bodies joined by joints. The geometric form of joint surfaces, bone levers, muscular force and neuron structures, among other things, determines the motion laws in the kinetic system work units

1 Research carried out within the project - Training Process Suit "BioKin", University of Rijeka, Science and Technology Park Rijeka - STeP Ri: steprisveuciliste@uniri.hr and Technology Transfer Office, Slavka Krautzeka 83/A, Rijeka E-mail: utt@uniri.hr and the entire kinetic chain. Kinetic chains are from the kinetics point viewed as a sequence of activation and transfer of individual segments or the whole body in the kinetic structure. The more kinetic chains in the kinetic structure are active, the kinetic structure is more complex. The spatial and temporal organization of most kinetic chains is complex. Complex kinetic structures take place in multiple joints under the influence of a large number of muscle groups or under the influence of a whole muscular system. At complex movements in the kinetic system, kinetic chains and kinetic muscle convolutions are formed. The kinetic muscle convolutions are formed by muscle agonists, antagonists and synergists that continue into each other over bones and fibrous formations. The kinetic chains in the kinetic system are even and can be long or short, open or closed (according to whether the ends of extremities are free or fixed to an object).

Thus, kinetic chains represent a set of anthropometric, anatomic-functional elements in the performance of particular kinetic structures. The dynamic moments of inertia of the human body change with the change of the relative body position, although with regard to their own central axes they are constant, regardless of the body position. This ensures a possibility for the moment of inertia of the body to be determined through its own moments of inertia of individual body parts and their aggregation into a whole (Steiner rule of the whole). To determine the dynamic moment of inertia of body parts, it is necessary to model the body parts with corresponding geometric bodies. ${ }^{2}$

The relevant dimensions and masses are determined with the knowledge of the harmonious distribution of masses and dimensions of human body parts. The dynamic behavior and motion of a body are proportional to the body's weight, and for its understanding it is necessary to know the distribution of its segmental masses and thus the dynamic moments of inertia. When studying the positions of kinetic chains, different biomechanical analyzes are often used in the formulation of motion of a general model. ${ }^{3}$ (Figure 1)

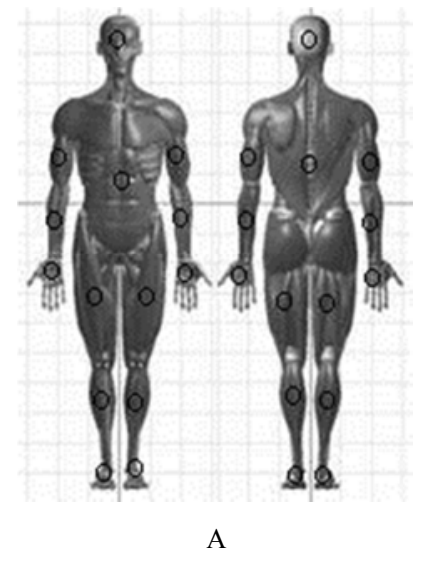

2 Dodig, M., Models and Modelling of Dynamic Moments of Inertia of Human Body, International Journal of Sports Science 2016, 6(6): 249-256.

${ }^{3}$ Dodig, M., Lateralizacija gibanja čovječjeg tijela - osnove kineziologije II. [Lateralization of Human Body Movement - The Basis of Kinesiology II.] University of Rijeka, PARADOX, d.o.o..Rijeka, 2019. 


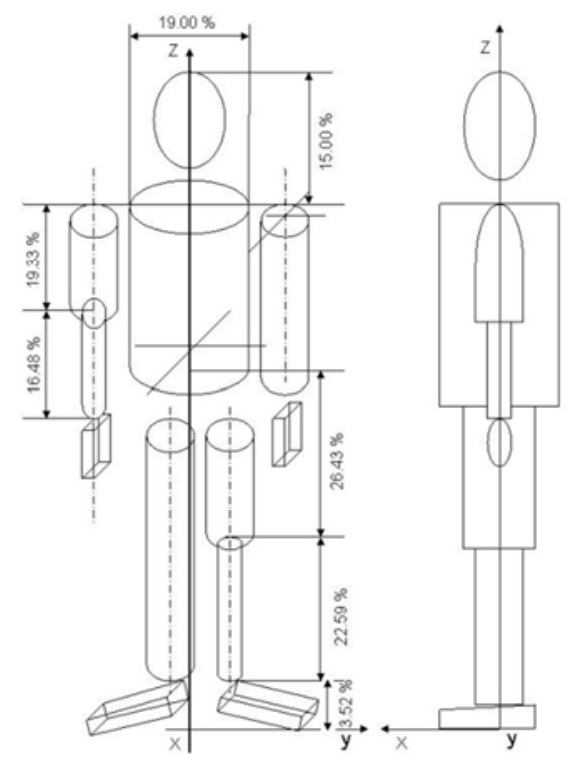

$\mathrm{B}$

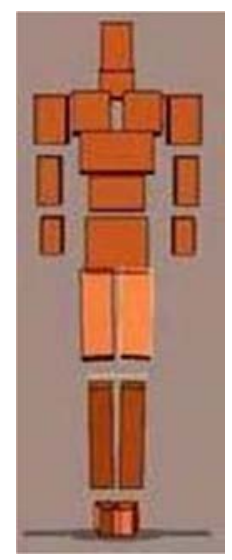

C

Figure 1. The human body models which were used in the analyses to calculate the dynamic moment of inertia of individual body segments or of the whole body are shown: A) model with markers B) model of simplified segments of the human body consisting of approximate geometric shapes, model with coordinates and C) models with computer-acquired body segments.

The dimensions of geometric bodies modeling body parts depend on the height and weight of the person, and on the mean density of the observed body part. Those dimensions can be conditionally divided into primary and secondary. The basic quantities which operate the model and modeling are the mass and height of the body or body parts and the coordinates of body parts mass centers. The output quantities of the modeling are the dynamic moments of inertia of body parts and moments of inertia of the whole body toward the central lateral axis y. Thus, in body motion we observe plane $\mathrm{x}, \mathrm{z}$, the dynamic moment of inertia of body parts towards the axis y becomes prominent (if the motion is forward).

With the help of approximate geometric shapes modeling individual body parts, it is possible to determine the expressions for approximate determination of dynamic moments of inertia of body parts toward the central lateral axis of the human body. To form these expressions, it is necessary to have data on the mass and dimensions of body parts (average values are often taken into account), although there are deviations from the actual ones. To avoid deviations, it is necessary to accurately determine the mass and dimensions of body parts, so it is necessary to measure the volume and dimensions of the body parts. Anthropometric measurements are used in the studying in five percentile groups that are supplemented by the regression equation Donskij D. D., Zacijorskij V. M. [15] (1979). By assuming any configuration of the subject a rigid body, by choosing simple geometric shapes (circular cylinders, rods and ellipsoids) for body parts, with the application of the Steiner rule it is possible to obtain a whole set of central moments of inertia.

The model for calculating the dynamic moment of inertia requires the determination of the position of the reference coordinate system with the main inertia axes, which have their starting point in the intersection of direction up-down, back-forth, left-right. Models of ellipsoid, a part of elliptic and rotating cylinder can be used. By using the Steiner rule, the inertia moments around the chosen inertia axes are calculated. The human body motion can be performed in dynamic and static conditions. In order to define the motion, it is necessary to know the mass distribution of that complex open or closed kinetic chain. In doing so, it is necessary to use the mathematical formulation of motion of a general model Korenev, G. B., [19] (1977).

On the basis of anatomical, physiological and biomechanical parameters of the human body a suit was proposed which ensures the movement of the body with different loads that are distributed according to the parameters of individual kinetic chains or body working units. The subject suit ensures mechanical properties adapted to the athlete's body, which is provided by the multilayer elastic material between which there is distributed silicone mass (of different profiles and configurations depending on the body part) with canals and ventilation openings.

1. Anatomical and anthropometric laws of the body: anatomic parameters of the locomotor system (bones, joints, muscles) and types of muscles, muscle groups and muscle functions. The basic elements and mechanisms of motion are defined by:

Bones from the biomechanical point of view behave as a supporting part of the body and form a lever system (types of lever).

Joints represent joined structures (types of joints) which from the biomechanical point of view represent points in the kinetic chain around which motion is created.

Muscles have the power to produce force with their contractions (force types), which they transfer to the bones (joined levers). The magnitude and distribution of force depend on the internal (type, number of muscle fibers and physiological muscle cross-section) and external (gravity, inertia and other bodies) factors.

The nervous system (perception, central nervous processing and transmission of information) has the function 
of creating, guiding and controlling motion. Body anthropometric parameters, external body shape, body length, length of body parts (legs, hands, torso), body weight, weight of individual body parts (leg, hand, torso). ${ }^{4}$

2. Physiological laws of the body: level and zone of stimulation (loads), optimal possibilities of elements (basic kinetic elements mass (kg), path/amplitude/(m) and time (s)), which affect the level and the stimulus and load zone with the aim of creating, accumulating and consuming energy (aerobic, aerobic-anaerobic, anaerobic), providing basic physiological values of the respiratory, cardiovascular, muscular and nervous systems. ${ }^{5}$

3. Biomechanical laws of the body: analysis and models of individual body parts or of the whole body (muscular force, direction of force, distribution of force) on individual body segments. From the biomechanical point of view, the dynamic moment of inertia in the kinetic structure plays an important role, and especially when moving in open and closed kinetic chains. The basic task of the study is directed at models and modeling the dynamic moment of inertia of individual body parts and of the whole body. There are some important definitions of the dynamic moments of inertia, based on approximate geometric shapes of individual segments and anthropometric quantities. For each body configuration, rigid body parts of simple geometric shapes (circular cylinders, rods and ellipsoids) were used for obtaining the model and modeling dynamic moments of inertia in kinetic chains of the human body. The proposed model for the head, neck and fist is modeled with ellipsoids, the model for the forearm, upper arm, lower leg and upper leg is modeled with rollers and the torso and foot are modeled with parallelepipeds. Knowing the sequential body configurations and the time shifts it is possible to calculate the dynamic moment of inertia.

The dynamic behavior of human motion when proportional body weight has been artificially increased requires knowledge of the distribution of its segmental masses and thus of the dynamic moments of inertia. Anthropometric measurements were used in the study in five percentile groups supplemented by the regression equation of Donski and Zaciorski, which determines the masses of body segments. Some important definitions of the dynamic moments of inertia were given. In addition, several body, arm and leg models were studied in which possible body, arm and leg configurations as well as influential mass distribution quantities were studied, based on which possible simplifications were performed. The choice of optimal models that are represented as the best approximation in a dynamic sense is described.

Body motion can be static or dynamic motion. To define the motion, it is necessary to know the mass distribution of that complex open kinetics chain. It is therefore necessary to propose a mathematical formulation of motion of a general model (Korenev G. B.: Wedenie $\mathrm{v}$ mehaniku čeloveka,

4 Dodig, M., Model and Modelling Physical Training Process. Rijeka: University of Rijeka, 2002

5 Dodig, M., Mechanisms Regulate Motion Human of Body - Basis Kinesiology, University of Rijeka, 2008.
Moskva, Nauka,_[19] (1977).

Body motion can be performed in a translation and rotational sense. For rotational motion, external dynamic moments of inertia need to be known. To calculate the external dynamic moments of inertia of body parts, it is necessary to observe the human body as a set of kinetic chains that are connected in the body with joints. ${ }^{6}$ Dimensions of geometric bodies modeling body parts depend on the height and weight of the person and on the mean density of the observed body part. Those dimensions can be conditionally divided into primary and secondary. In body motion we observe plane $\mathrm{x}, \mathrm{z}$, the dynamic moment of inertia of body parts towards the axis y becomes prominent (if the motion is forward).

With the help of approximate geometric shapes modeling individual body parts, it is possible to determine the expressions for approximate determination of dynamic moments of inertia of body parts toward the central lateral axis of the human body. To form these expressions, it is necessary to have data on the mass and dimensions of body parts (average values from table 1 are taken into account), although there are deviations from the actual ones. To avoid deviations, it is necessary to accurately determine the mass and dimensions of body parts, so it is necessary to measure the volume and dimensions of the body parts.

The input quantities are the mass and height of the body and coordinates of the body parts mass centers from which the dynamic moments of inertia of the body parts and moments of inertia of the whole body are obtained towards the central lateral axis. The input quantities are the mass and height of the body and coordinates of the body parts mass centers from which the dynamic moments of inertia of the body parts and moments of inertia of the whole body are obtained towards the central lateral axis $\mathrm{Y}_{\mathrm{s}}$. It is known that body mass is given in kilograms, height in meters, and the value of calculated moments of inertia is expressed in $\mathrm{kgm}^{2}$.

Models of the human body made up of the abovementioned shape configurations served as a starting point in the conceptual definition. Figure 1 shows the center points of individual segments and anthropometric quantities expressed in proportion to the height of the body with a net model of simplified segments.

When achieving the subject invention, more precisely when determining the body load index for each type of activity, hypotheses based on basic biological, physiological and biomechanical laws which play an important role in the realization of motion were set. It is known that the locomotor system consisting of bones, joints, muscles and the central nervous system is responsible for body motion. Their function is subordinated to the demands of motion, and it served as a basis for the project design for the training process suit.

The initial state is defined based on the maximal possibilities by calculating the percentage for each workout zone. These

6 Kinetic chain - a formation that comprises body parts with associated joints. There are open and closed kinetic chains. 
percentages represent the initial values on the basis of which the transformation process is programmed, according to the progressively continuous and progressively discontinuous method. This ensures an increase in load at certain time intervals, affecting the development of bodily and functional abilities of the person in the zone of anaerobic, aerobicanaerobic and aerobic capabilities. The workout zones are determined by the distribution of the result obtained in a particular motion or a repetitive motion, which determines the percentage defining the intensity in a particular workout zone. The anaerobic workout zone ranges from $70 \%$ to $100 \%$ of the maximum load, corresponding to submaximal and maximum strength, the aerobic-anaerobic ability zone (aerobic-anaerobic workout zone) is at $30 \%$ to $70 \%$ of the maximum load, corresponding to the repetitive submaximal strength or endurance in strength, and the aerobic ability zone ranges from $1 \%$ to $30 \%$ of the maximum, corresponding to endurance of the body. Load indexes are based on the type of stimulus that is to be distributed to the body. According to the present invention, it is desirable that the load index for aerobic stimulation is 3 , for aerobic-anaerobic stimulation 6 , and for anaerobic stimulation 12 .

In achieving the subject invention, we came to notice that the load with index 3 creates the possibility of achieving a heart rate of 90 to 150 beats per minute, that index 6 generates a pulse frequency of 140 to 180 beats per minute and that index 12 generates a pulse frequency of 170 to 220 beats per minute. The results relate to the same stimulation of running for 5 minutes (running $7 \mathrm{~km} / 1$ hour). Accordingly, when calculating the thickness i.e. weight of the second layer of the present invention and the goal of obtaining a training suit for aerobic, aerobic-anaerobic or anaerobic training, it is desirable to use the above-mentioned load indexes.

The obtained results represent the zones of workout and effects on the metabolic processes. Therefore, the suit with index 3 - aerobic process is intended for long workouts of low intensity (running, rowing, cross-country skiing - mostly cyclical motions). Suit with index 6 - aerobic-anaerobic process is intended for intermediate mid-intensity cyclicacyclic motion (soccer, handball, basketball, etc.). Suit with index 12 - anaerobic process, is intended for short maximum intensity acyclic motion (martial arts, throwing discipline in athletics etc.).

\section{Basic Laws, Mechanical Analysis and Verification of the Training Process Suit Function}

The dynamic moments of inertia of the human body change with the change of the relative body position, although with regard to their own central axes they are constant, regardless of the body position. This ensures a possibility for the moment of inertia of the body to be determined through its own moments of inertia of individual body parts and their aggregation into a whole (Steiner rule of the whole).
To determine the dynamic moment of inertia of body parts, it is necessary to model the body parts with corresponding geometric bodies. The relevant dimensions and masses are determined with the knowledge of the harmonious distribution of masses and dimensions of human body parts (table 1).

The height of individual body parts is expressed as percentages of the total body height and the distribution of body parts mass values is derived according to DonskiZaciorski.

Modeling body parts is done with geometric bodies through which dynamic moments of inertia can be calculated:

The ellipsoid model is used in the analysis of the head, neck and fist $(1,2)$. The roller model is used in the analysis of the forearm, upper arm, lower leg and upper leg $(3,5,6)$. The parallelepiped model is used in the analysis of the torso and feet $(4,7)$.

Overview of the segment model and expressions for calculating central moments of inertia.

Head and neck

$$
I_{Y S O}=0.2 \mathrm{~m}\left(b^{2}+d^{2}\right)(\mathrm{b}=\mathrm{c})
$$

Fist

$$
I_{Y S O}=0.2 m_{p}\left(b^{2}+d^{2}\right)(\mathrm{b}=\mathrm{c})
$$

Upper arm. Forearm

$$
I_{Y S O}=m_{n}\left(\frac{r^{2}}{4}+\frac{l^{2}}{12}\right)
$$

Upper

Torso Central

$$
I_{Y S O}=\frac{m}{12}+\left(l \frac{2}{1}+l \frac{2}{3}\right)
$$

Lower

Upper leg

$$
I_{Y S O}=m_{n} \frac{l^{2} r}{12}
$$

Lower leg

$$
I_{Y S O}=m_{p} \frac{l^{2}}{12}
$$

Foot

$$
I_{Y S O}=\frac{m_{S}}{12}+\left(l \frac{2}{3}+l \frac{2}{1}\right)
$$

In the subject invention, the term body segments refers to sequential configurations of the body related to the: head, neck, fists, forearms, upper arms, lower legs, upper legs, torso and feet.

In the subject invention, the term suit layer segments refers to the suit layer segments which correspond to individual body segments - Figure 2 .

The subject invention refers to a training suit that is comprised of three layers:

i. The first, base layer, which adheres directly to the skin 
and has an elasticity factor that will satisfy the conditions of necessary flexibility and moisture absorption;

ii. The second, central layer, which ensures the distribution of proportional weight on individual body segments. Namely, the weight of this layer is proportionally distributed in the manner that the weight of each individual segment of the second layer that corresponds to each individual body segment is equal to the increase of weight for that individual body segment;

iii. The third, outer layer, which is waterproof but simultaneously moisture-permeable and is also elastic.

The role of the first layer is to absorb moisture. It is preferred that a fabric of elastine that fulfills these criteria is used. Such a fabric can be selected from materials such as Lycra, Spandex, etc.
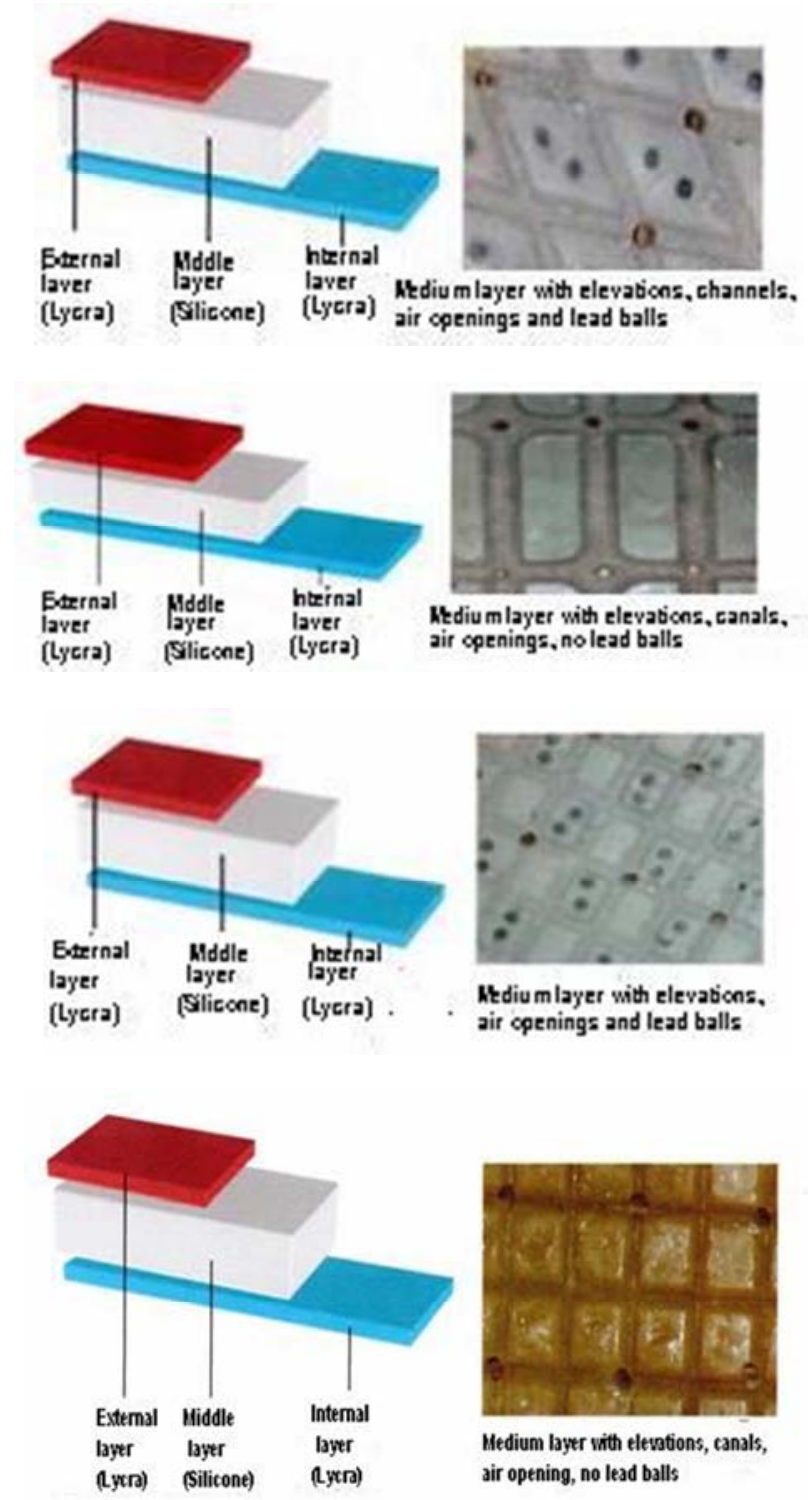

Figure 2. Outer layer (Lycra), middle layer (Silicone) with a silicon configuration with canals and air openings and with elevations with lead balls, inner layer (Lycra).
It is preferable that the second layer of the suit is made of a single-component elastic silicon that is cast according to the structure of the mould for individual segments of the body, depending on the mass of the individual segments of the body. ${ }^{7}$ The moulded silicon segments of the suit's second layer have a thickness of 1 to 5 millimeters, depending on the mass of the individual segments of the body. The silicon segments have a shape dependent on the part of the body for which they are intended. The silicon segments on the surface toward the body have protrusions, canals and openings (the openings pass through the entire thickness of the silicon), while the outer surface is smooth. Moulds are made for individual segments of the body, which have protrusions, canals and ventilation openings. The protrusions have the assignment of accommodating lead balls or lead dust and of ensuring an adequate canal depth, which serves for the circulation of air or perspiration. The circular openings that likewise serve for ventilation have a radius of 1 to 2 millimeters and pass through the entire thickness of the silicon layer, and are evenly distributed on the silicon segments. If the embodiment requires a greater weight of silicon due to the weight of individual segments, it is then necessary to place lead balls or lead dust into the protrusions found in the silicon in order to achieve the necessary weight, allowing the silicon to remain the same thickness. The singlecomponent elastic silicon is a permanently elastic mass, which originates from a gelatin structure of silicon, and hardens and assumes an elastic structure when it comes into contact with moisture. The permanently elastic mass has a polysiloxane base (it hardens if used with acid), is resistant to mildew (according to ISO $846 \mathrm{~A}$ and B), moisture, detergents and chemicals, and can be modeled well on most surfaces without the use of a base coat.

It is preferable that the third layer of the suit uses a material with a system of microscopic holes that will withhold rain, snow and wind, but will simultaneously release moisture. ${ }^{89}$ These criteria are fulfilled by, for example, a fabric made of elastine, referred to as Lycra, which is a highly elastic fabric that comprises polyamide fiber $80 \%$ and elastine fibers $20 \%$. Due to its four-way stretch, it is favorable for the production of all types of garments that require elasticity and the possibility of adhering to the body. 10

\footnotetext{
7 Silicones are polymeric silicon compounds, created by controlled orthosilicate acid condensation. They got their name due to the resemblance to ketones (silicone ketones), due to the similar general formula $\mathrm{R}_{2} \mathrm{C}=\mathrm{O}$. It should be noted that silicones do not have any physical or chemical similarity to ketones. In the manufacture of the suit, silicone transparent is used, a one-component permanent elastic mass which is formed by curing in contact with moisture from the air. The permanent elastic mass with a polysiloxane base (hardened by acid), resistant to mildew (according to ISO $846 \mathrm{~A}$ and B), moisture, detergent and chemicals, is well modeled on most surfaces without the use of the base coat.

8 The third, final layer is watertight (materials with a microscopic hole system will withold rain, snow and wind, but will also release the moisture), elastic and strong enough. These criteria are met by the elastin fabric.

9 Lycra - Highly elastic fabric made of polyamide fiber $85 \%$ and elastic fiber $15 \%$. Due to its elasticity in 4 directions, it is suitable for making all kinds of clothing models which require elasticity and ability to adhere to the body.
} 
Due to the selection of the aforementioned materials for all three layers, the subject suit conforms to the anatomic morphology of the body.

The suit can be in the form of a jumpsuit. Further, the suit can have closed ends at the feet and palms. An opening for putting on and taking off the suit can be situated in the chest area of the suit. The suit can be a two-piece suit or can be made for only a certain part of the body, e.g. for the legs or the upper body. Moreover, one option may be that the suit further includes an elastic reinforcement around the waist. Such a suit would mainly be intended for use in physical therapy.

Furthermore, the suit can have a hood that does not contain the silicon mass. In specific parts of the suit, certain types of sensors for monitoring the training process (electrodes, pulse rate meters, etc.) can be embedded into the silicon.

Due to the functionality and flexibility of the suit, it is desired that all layers of the suit are made of individual segments and then joined into a whole. The segments are arranged on the body in such a manner that enables unobstructed and full amplitude movement in the major joints of the body (shoulder joint, elbow, hip, knee, wrist, ankle and spine). The suit can be cast from one or two parts, but in the latter case, its function and flexibility would be questionable.

According to the subject invention, the weight of the suit, i.e. the weight of the second layer of the suit, is distributed according to biomechanical, anatomic and functional characteristics. It is desirable that the thickness of the second layer does not exceed $5 \mathrm{~mm}$, as to not perturb the elasticity of the second layer of the suit. In cases requiring great exertion, the weight of the second layer of the suit, and therewith the thickness of the second layer of the suit, is supposed to be greater than $5 \mathrm{~mm}$ in certain sections in order to ensure the proportional distribution of the suit's weight on the entire body. In such cases, lead balls or lead dust can be inserted into the protrusions of the second layer of the suit, which have the function of increasing the proportional weight at those portions without increasing the thickness of the second layer of the suit at those same portions of the body. Namely, lead dust or lead balls are added if the calculated weight of the segment exceeds the weight that is possible to achieve with a 5-millimeter thickness of the second layer. Thus, lead dust or lead balls are added into the segments of the suit where it is necessary to achieve a greater weight of the segment of the suit, without compromising the $5 \mathrm{~mm}$ maximum thickness of the second layer of the suit. For some segments (the lower leg, forearm or other segment) and according to calculations, it is often unnecessary to execute a weight compensation with lead balls or lead dust, while, for example, the necessity for increasing the weight of the torso segment will often be present. Taking into account that lead dust or lead balls are inserted into the protrusions of the silicon portion of the suit, an additional weight of an individual segment is achieved without impairing the elasticity of the silicon's surface.

The thickness and weight of the second layer of the suit are determined by calculating the weight gain of each individual segment of the suit's second layer. The weight gain of each individual segment of the suit's second layer is calculated based on the data of the proportional distribution of the weight of the body for each individual segment of the body and the load index.

$$
\mathrm{OP}=\mathrm{Kt} \times \mathrm{IND} / 100
$$

where:

OP is the weight gain that actually indicates the weight of the suit's second layer that is necessary for an individual segment of the body;

$\mathrm{Kt}$ is the proportional distribution of the weight of the body for each individual segment;

IND is the load index.

It is desirable that the load indexes used are the integers 3, 6 or 12 .

Upon calculation of the weight of each individual segment of the suit's second layer, the thickness of each individual segment of the suit's second layer is then calculated. The thickness of a segment of the suit's second layer is calculated using the volume of the segment of the suit's second layer.

$$
\mathrm{V}=\mathrm{OP} / \mathrm{g}
$$

where:

$\mathrm{V}$ - volume of the segment of the second layer;

OP is the weight gain that actually indicates the weight of the suit's second layer that is necessary for an individual segment of the body;

$\mathrm{g}$ - density of the material used for the suit's second layer.

$$
\mathrm{P}=\mathrm{O} \times \mathrm{Kv}
$$

where:

$\mathrm{P}$ - area of the segments of the second layer;

$\mathrm{O}$ - measured circumference of the segment of the body;

$\mathrm{Kv}$ is the proportional distribution of the height of the body for each individual segment.

$$
\mathrm{d}=\mathrm{V} / \mathrm{P}
$$

where:

$\mathrm{d}$ - thickness of the segment of the suit's second layer;

$\mathrm{V}$ - volume of the segment of the second layer;

$\mathrm{P}$ - area of the segments of the second layer.

In the event that for the weight of an individual segment, such a weight is necessary that the thickness of the suit's second layer exceeds $5 \mathrm{~mm}$, in that individual segment of the suit's second layer, lead dust or balls are added in the amount necessary to achieve the calculated weight of the individual segment of the suit's second layer.

Parameters $\mathrm{Kt}$ and $\mathrm{Kv}$ were calculated based on the method for determining body mass distribution. One of the modern methods for determining body mass distribution and dynamic features of segments is the Donski and Zaciorski method, based on the estimation of the volume determined by the radioisotope method. From the statistical analysis of the results thus determined, the authors defined the regression 
paths for each segmented part and based on that determined the corresponding coefficients by which the desired masses and heights can be calculated.
The corresponding dimensions and masses are determined using the knowledge of the harmonic distribution of mass and the dimensions of the parts of the human body (Table 1).

Table 1. An overview of anthropometric values of body parts and body mass (Donskij D., Zacijorski V. M.: Biomechanics, Publ. "Fizkultura i sport”, Moscow 1979).

\begin{tabular}{llll}
\hline \multirow{2}{*}{ BODY PART } & \multicolumn{2}{l}{ Height in (\%) of total height (D) } & Mass in (\%) of total mass (T) \\
\cline { 2 - 4 } & MEN & WOMEN & 1,371 \\
\hline Foot & 3,52 & 3,50 & 14,165 \\
Upper leg & 26,43 & 26,10 & 4,330 \\
Lower leg & 22,59 & 22,00 & 0,61 \\
Fist & 10,44 & 10,20 & 2,707 \\
Upper arm & 19,33 & 18,40 & 1,615 \\
Forearm & 16,48 & 15,58 & 15,956 \\
upper & & & 16,327 \\
Torso central & 31,50 & 32,50 & 11,174 \\
lower & & & 4,936 \\
Length of foot & 15,42 & 15,10 & 6,94 \\
Head with neck & 15,90 & 15,92 & 43,457 \\
Torso width & 19,00 & 20,00 & \\
\hline
\end{tabular}

The height of individual body parts are expressed in percentages of the total height of the body, and the distribution of mass value of the body parts was carried out according to Donskij-Zacijorskij and is expressed in percentages for an individual segment. For this necessity, the program QBASIC was used for calculating the parameters of height and weight of the individual segments of the body based on the height and weight of the entity.

Accordingly, the methodology of the conceptual solution in the design of the Training Process Suit. By using the information from the methodological settings, the parameters and the model for making the suit were determined:

(1) On the basis of anatomic and anthropometric parameters.

Anatomic and anthropometric parameters (height, weight of individual body parts and of the whole body).

The weight and size proportions of individual segments of the body or parts of the body were calculated. Based on the obtained parameters for the male and female bodies, computer programs were made. For this need, the QBASIC program was used to calculate the size and weight parameters of individual body segments based on the height and weight of the entity.

(a) Program for calculating the size and weight of individual male body segments

(b) Program for calculating the size and weight of individual female body segments

(2) On the basis of physiological and biomechanical parameters:

Biomechanical parameters - cyclic and acyclic motion (type of motion)

Physiological parameters - aerobic, aerobic-anaerobic and anaerobic stimuli, load indexes based on the geometric progression of metabolic processes were determined (aerobic - index 3, aerobic-anaerobic - index 6 and anaerobic - index 12). For this purpose too, the QBASIC program was used to calculate the weight gain for individual segments according to load indexes (index $-3,6$ or 12).

a) Program for calculating the weight gain for individual segments according to load indexes for the male body b) Program for calculating the weight gain for individual segments according to load indexes for the female body

c) Program for calculating the mass, volume and thickness of the silicone with and without the filling with lead balls or lead dust.

(1) Program for calculating the size and weight of individual male body segments:

(2) Program for calculating the size and weight of individual female body segments:

(3) Program for calculating the weight gain for individual segments according to load indexes for the male body:

(4) Program for calculating the weight gain for individual segments according to load indexes for the female body:

(5) Program for calculating the mass, volume and thickness of the silicone with and without the filling with lead balls:

Example 1. Calculating the parameters of weight gain for individual segments according to the load indexes of the male body (Table 2)

Based on the parameters of Table 1, the proportional distribution of the height and weight of the segments of the body has been calculated based on the formula:

$$
\mathrm{Kv}=\mathrm{D} \times \mathrm{Xv} / 100
$$

where:

$\mathrm{Kv}$ is the proportional distribution of the height of the body for each individual segment;

$\mathrm{D}$ is the percentage of involvement of each segment of the body in the total height of the body according to Table 1;

$\mathrm{Xv}$ is the height of the male body.

$$
\mathrm{Kt}=\mathrm{T} \times \mathrm{Xt} / 100
$$

where:

$\mathrm{Kt}$ is the proportional distribution of the weight of the body for each individual segment;

$\mathrm{T}$ is the percentage of involvement of each segment of the body in the total weight of the body according to Table 1;

$\mathrm{Xt}$ is the weight of the male body. 
Table 2. Overview of Bodys Segment Increment in Weight by Index of load.

\begin{tabular}{|c|c|c|c|c|c|}
\hline BODY HEIGHT & $184 \mathrm{~cm}$ & & & & \\
\hline BODY WEIGHT & $105 \mathrm{~kg}$ & & & & \\
\hline \multirow{2}{*}{ BODY PART } & \multicolumn{2}{|c|}{ PROPORTIONAL DISTRIBUTION OF THE BODY } & \multicolumn{3}{|c|}{ WEIGHT GAIN (OP) (kg) } \\
\hline & (Kv) HEIGHT (cm) & Kt WEIGHT (kg) & IND 3 & IND 6 & IND 12 \\
\hline HEAD - NECK & 29,256 & 7,287 & & & \\
\hline UPPER ARM & 35,567 & 2,842 & 0,053 & 0,171 & 0,341 \\
\hline FOREARM & 30,323 & 1,696 & 0,051 & 0,102 & 0,204 \\
\hline FIST & 19,210 & 0,645 & 0,193 & 0,039 & 0,077 \\
\hline TORSO UPPER PART & 19,136 & 16,754 & 0,503 & 1,005 & 2,011 \\
\hline TORSO CENTRAL PART & 22,264 & 17,144 & 0,514 & 1,029 & 2,057 \\
\hline TORSO LOWER PART & 16,560 & 11,733 & 0,352 & 0,704 & 1,408 \\
\hline UPPER LEG & 48,631 & 14,873 & 0,446 & 0,892 & 1,785 \\
\hline LOWER LEG & 41,565 & 4,547 & 0,136 & 0,273 & 0,546 \\
\hline FOOT & 6,477 & 1,440 & & & \\
\hline TOTAL GAIN & & & 3,248 & 4,215 & 8,329 \\
\hline
\end{tabular}

Based on the calculated weight gain for each individual segment of the body, the weight, thickness and height of the silicon for each individual segment is calculated. The calculation is shown on an example with the forearm with a load index of 6.

The proportional distribution of the height and weight of the forearm:

$$
\mathrm{Kv}=30,323 \mathrm{~cm} \quad \mathrm{Kt}=1,696 \mathrm{~kg}
$$

$$
\begin{gathered}
\text { FOREARM: OP }=\text { Kt } \times \text { IND 6/100 }=1,696 \mathrm{~kg} \times 6 / 100= \\
0,102 \mathrm{~kg}
\end{gathered}
$$

where:

OP is the weight gain that actually indicates the weight of silicon necessary for an individual segment of the body;

IND 6 is the load index.

In order to obtain the weight of silicon and eventually the weight of the lead balls for the forearm, it is necessary to calculate the following:

$$
\begin{aligned}
& \mathrm{V}=\text { the volume of silicon }(\mathrm{OP} / \mathrm{g}) \\
& \mathrm{d}=\text { the thickness of silicon }(\mathrm{V} / \mathrm{P})
\end{aligned}
$$

$\%=$ the percent of silicon and lead balls in a segment where:

$\mathrm{g}$ is the density of silicon;

$\mathrm{V}$ is the volume of the silicon segment;

$\mathrm{P}$ is the area of the silicon segment.

\section{CALCULATION FOR THE FOREARM}

$$
\begin{gathered}
\mathrm{V}=\mathrm{OP} / \mathrm{g}=0,102 \mathrm{~kg} / 1,9 \mathrm{~kg} / \mathrm{dm}^{3}=0,0536 \mathrm{dm}^{3}=53,6 \mathrm{~cm}^{3} \\
\mathrm{P}=\mathrm{O} \times \mathrm{Kv}=30,323 \mathrm{~cm} \times 30,323 \mathrm{~cm}=919,48 \mathrm{~cm}^{2}
\end{gathered}
$$

Where 0 is the measured circumference of the segment of the body.

It can be noted that 0 is equal to $\mathrm{Kv}$, so that the circumference of each segment, and thus of the forearm, does not have to be measured (the square of the area was used, which does not significantly deviate from actual values).

$$
\mathrm{d}=\mathrm{V} / \mathrm{P}=53,6 \mathrm{~cm}^{3} / 919,48 \mathrm{~cm}^{2}=0,0583 \mathrm{~cm}=5,8 \mathrm{~mm}
$$

Taking into account that the calculated thickness of silicon for this segment of the body exceeds the desired thickness of silicon of up to $5 \mathrm{~mm}$, it is necessary to execute the distribution of weight gain on the silicon and lead balls for this segment of the body. Retaining the $5 \mathrm{~mm}$ thickness of silicon, the remaining thickness of $0,8 \mathrm{~mm}$ must be compensated with lead balls or lead dust.

The portion of each thickness is calculated, in \%:

$\% \mathrm{~S}=$ the percentage of silicon in the thickness of the layer $\% \mathrm{~S}=5,0 \mathrm{~mm} \times 100 / 5,8 \mathrm{~mm}=86,21 \%$

$\% \mathrm{~K}=$ the percentage of lead balls in the thickness of the layer

$$
\% \mathrm{~K}=0,8 \mathrm{~mm} \times 100 / 5,8 \mathrm{~mm}=13,79 \%
$$

Based on the results of $\% \mathrm{~S}$ (the percentage of involvement of silicon in the thickness of the layer) and $\% \mathrm{~K}$ (the percentage of involvement of lead in the thickness of the layer), their percentage of involvement in the weight obtained by the load index is calculated $(\mathrm{OP}=0,102 \mathrm{~kg})$.

Lastly, the weight belonging to the mass of the silicon and the weight belonging to the mass of the lead balls or lead dust is calculated from the weight gain (OP).

$\% \mathrm{TS}=$ the weight belonging to the silicon

$\% \mathrm{TK}=$ the weight belonging to the lead balls or lead dust

$\% \mathrm{TS}=\mathrm{OP} \times \% \mathrm{~S} / 100=0,102 \mathrm{~kg} \times 86,21 / 100=$ $0,0879342 \mathrm{~kg}$

$\% \mathrm{TK}=\mathrm{OP} \times \% \mathrm{~K} / 100=0,102 \mathrm{~kg} \times 13,79 / 100=$ $0,0140658 \mathrm{~kg}$

Accordingly, the expression TS $+\mathrm{TK}=\mathrm{OP}$ gives $(0.08793$ $\mathrm{kg}+0.01406 \mathrm{~kg}=0.0101 .99 \mathrm{~kg}$ )

Upon calculation of the weight and thickness of the second layer of each individual segment, each individual segment of the second layer (2) is cast according to the structure of the mould for an individual segment, depending on the mass of an individual segment. In this example, a single-component silicon for casting the second layer of the suit was used. The cast silicon segments (2) have a thickness of 1 to 5 millimeters, depending on the mass of the individual segment. The silicon segments (2) have a shape depending on the part of the body for which they are intended. On the surface toward the body, the silicon segments (2) have protrusions (6), canals (5) and openings (4) (the openings 
pass through the entire thickness of the silicon), while the exterior portion of the suit is smooth, as can be seen on
Figure $3 \mathrm{a}, \mathrm{b}$ and $\mathrm{c}$.

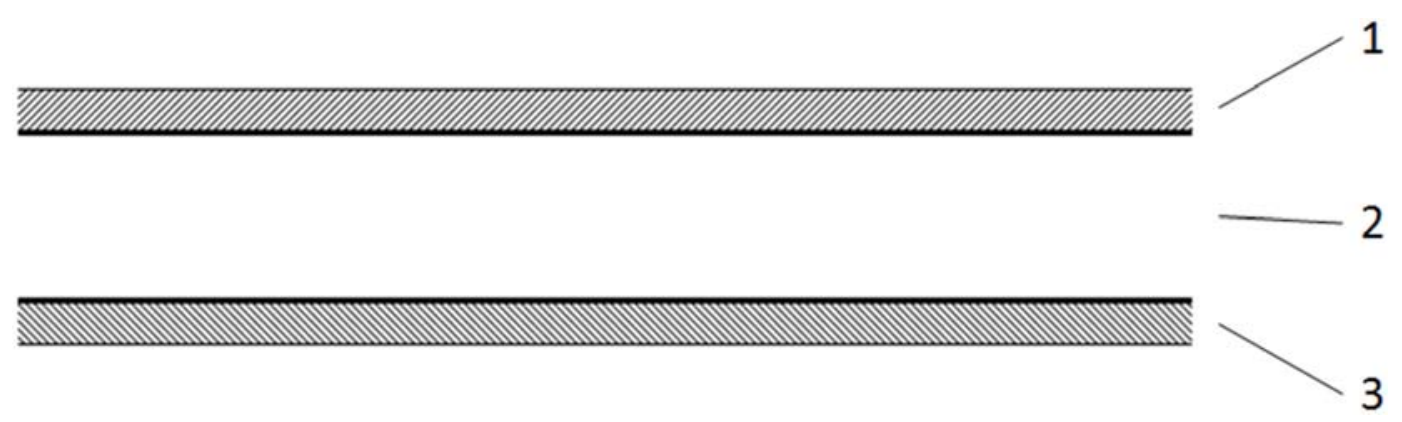

$3 \mathrm{a}$

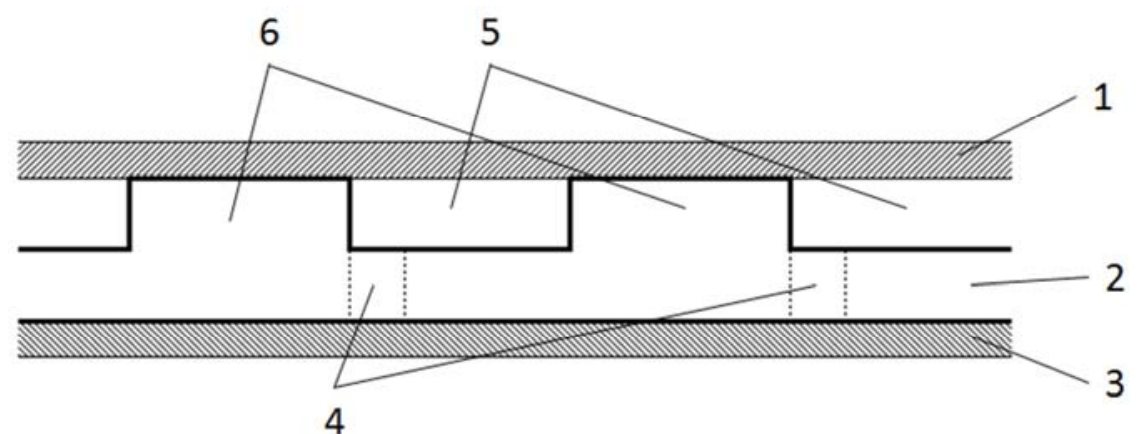

$3 b$
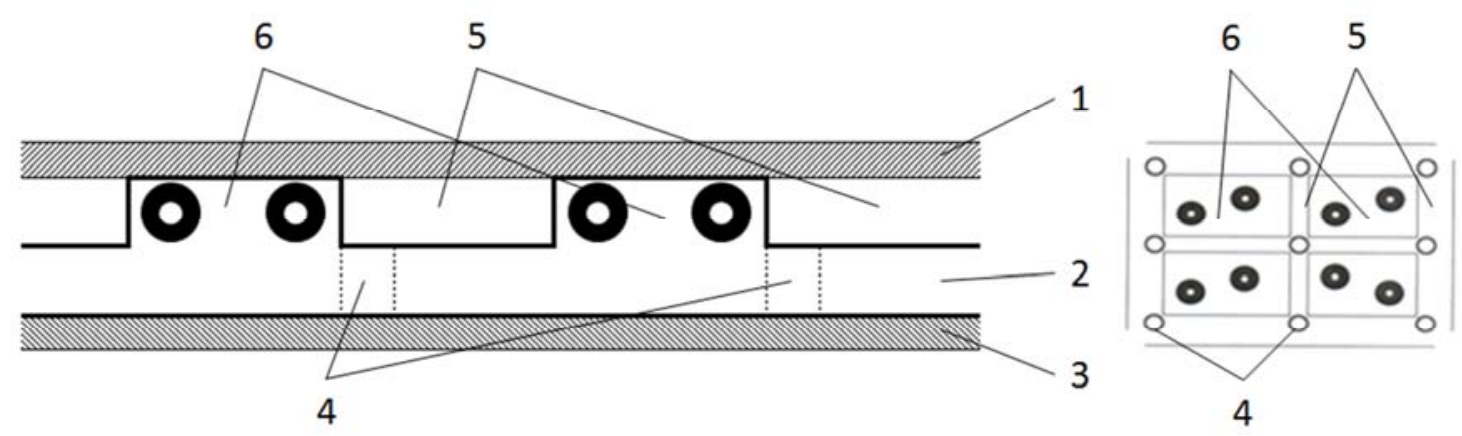

$3 \mathrm{c}$

Figure 3. Cross-sectional view of all three layers of the subject suit, Figure $3 b$-cross-sectional view of all three layers of the suit showing the protrusions, canals and openings in the second layer of the suit, Figure $3 \mathrm{c}$ - cross-sectional view of all three layers of the suit showing the protrusions, canals and openings in the second layer of the suit and lead balls in the protrusions of the second layer of the suit.

Example 2: Calculating the parameters of weight gain for individual segments according to the load indexes of the male body (Table 3 ).

Table 3. Weight parapmeters of individual body parts (parameters for the criterion, weight $100 \mathrm{~kg}$, height $180 \mathrm{~cm}$, load index 6).

\begin{tabular}{llll}
\hline FRONT SIDE OF THE BODY & BACK SIDE OF THE BODY & 210 \\
\hline shoulder & 210 & shoulder & 250 \\
upper arm & 250 & upper arm & 150 \\
forearm & 150 & forearm & 600 \\
chest $(310 \times 2)$ & 620 & chest $(310 \times 2)$ & 450 \\
hip $(230 \times 2)$ & 460 & hip $(230 \times 2)$ & 960 \\
upper leg $(400 \times 2)$ & 800 & upper leg $(400 \times 2)$ & 580 \\
lower leg (180x2) & 360 & lower leg $(180 \times 2)$ & 3.200 \\
TOTAL WEIGHT $=6.050 \mathrm{~kg}$ & 2.850 & & \\
\hline
\end{tabular}

Based on the obtained results, it is possible to obtain a graphic display of the distribution of the parts of the body as shown in Figures 4A and 4B. 


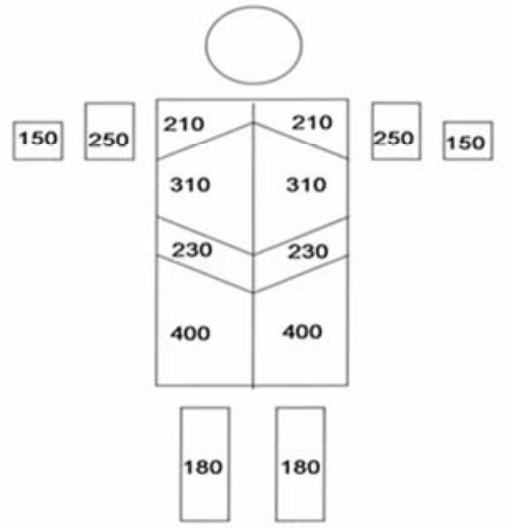

A

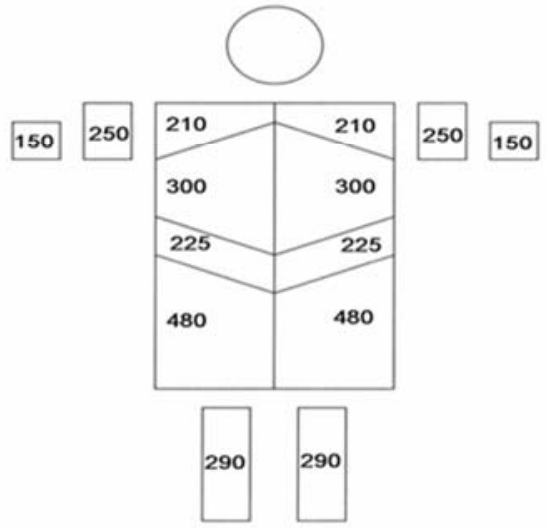

B

Figure 4. Models of the human body used as the conceptual basis for the analyses of individual body segments or of the whole body. The figure shows the central points of individual segments and anthropometric quantities expressed as percentages of body height with the net model of simplified segments. Afront side of the body, $B$ - back side of the body.

The silicon sheets of the segments of the suit's second layer (2) are trimmed with elastine, which serves for joining these segments by sewing (Figures 5,6). On the front side of the body, the segments are joined by sewing the trims (Figure $6 \mathrm{~A}$ ), and further are sewn on the interior elastine (3). On the front side of the suit's second layer (2), formed in the stated manner, the exterior elastine (1) is secured by sewing, which is sewn from parts in accordance with the model of the suit, along the lateral seams of the suit. The back side of the suit (Figure 6B) is created in the same manner, and then the front and back sides are joined along the lateral seams, to result in the final form of the suit. On a suit joined as stated, sleeves are added by joining the same along the seams. A display of the final form of the front and back sides of the suit is shown on Figure $7 .^{10}$

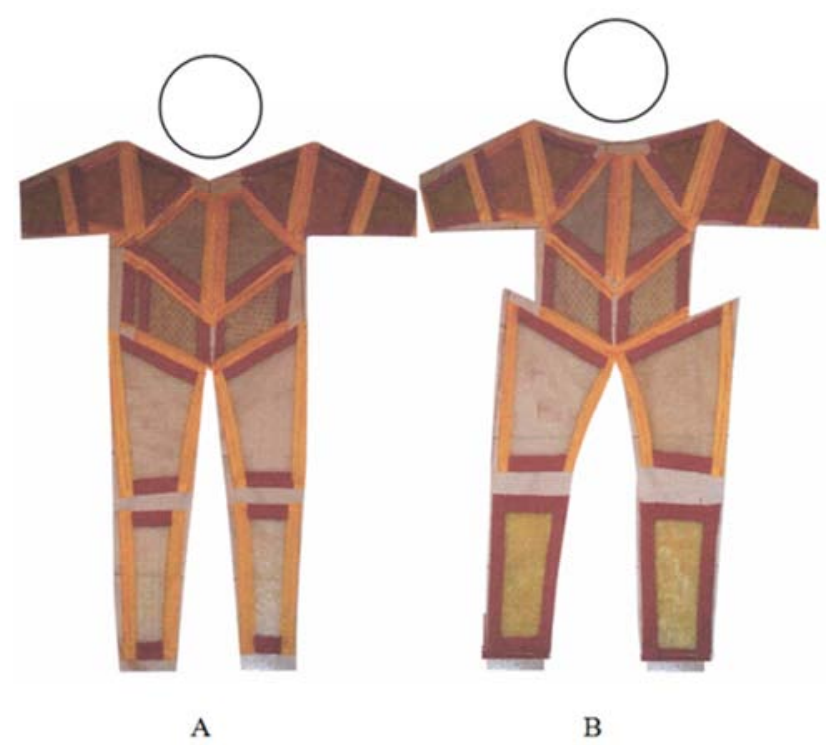

Figure 5. Connected segments of the second layer for the whole body: Afront side, $B$ - back side.

10 Dodig, M., A Suit for the Physical Training Process, State Intellectual Property Office of the Republic of Croatia. Consensual patent Zagreb, 18 September 2015

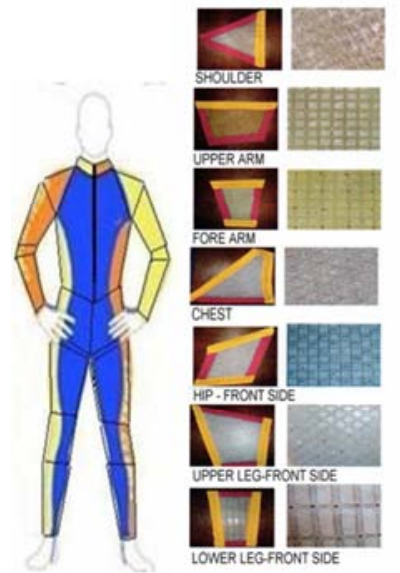

A

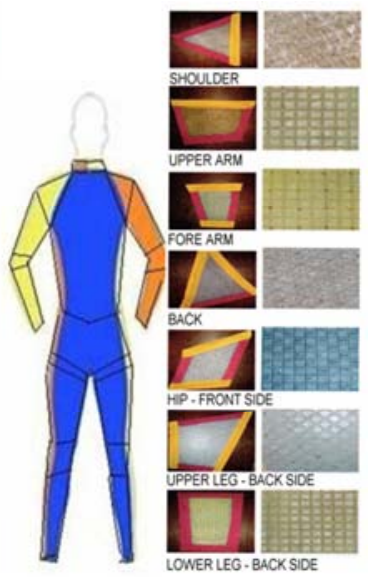

B
Figure 6. Segments of the second layer of the suit (shape, surface and structures of the silicone, front side of the body) figure and segments that shape it, $B$ - back side of the body and It can be noticed that there are lead balls on the structure of individual segments (torso, chest, back and hips) which have the task of increasing the weight and not increasing the thickness of the silicone.

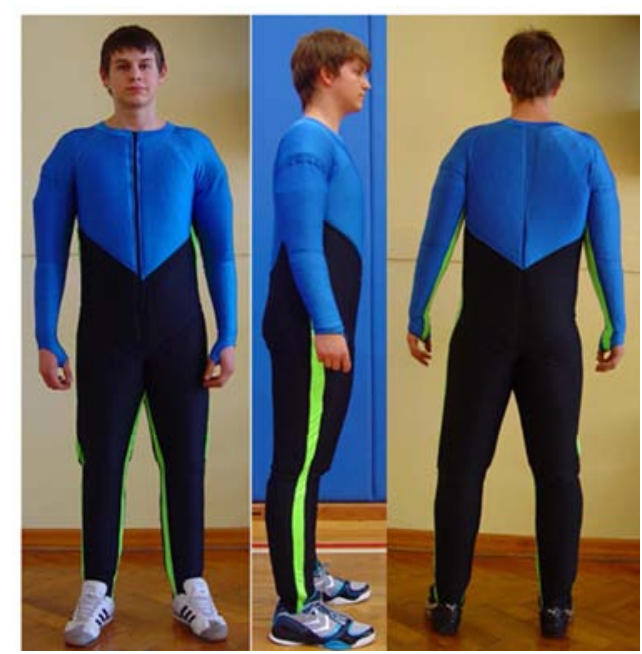

Figure 7. The training process suit: $A$ - front side, $B$ - lateral side, $C$ - back side. 
The application of the suit for the physical training process for the development of motoric abilities, physical fitness of the body and body movement techniques (Figure 8, 9).

Superior accomplishments in the training process are achieved with the transformation of energetic and informational properties of the body with specific movement structures. The transformation process of certain anthropologic properties is a dynamic process that is characterized by qualitative and quantitative changes in a time duration. The transformations of anthropologic properties refer to the variability and covariability that is manifested within and between the structure during the transversal and longitudinal time duration.

The practical check of the training process suit prototype was performed by recording, measuring and testing the applicative values of the suit in walking, running, on a bicycle simulator, a rowing simulator and on bench step-ups. The measurement criteria were unified for the variant in the sports equipment and in the suit. Equivalent motion (walking, running, pedaling, rowing and step-ups) was performed under the same conditions (same load and duration of motion). Based on the results obtained with the POLAR measuring instrument, we obtained heart rate frequencies shown in an analog form for each variant of motion. Finally, we calculated the zones expressed in percentages, which are shown graphically. These values indicate that for the same motion with the same load on the simulator and with the same duration of motion, significant physiological stimuli of the body take place, which in part was the goal of the suit.

Overview of obtained testing results in walking, running, step-ups, pedaling, rowing - Figures 8 and 9.

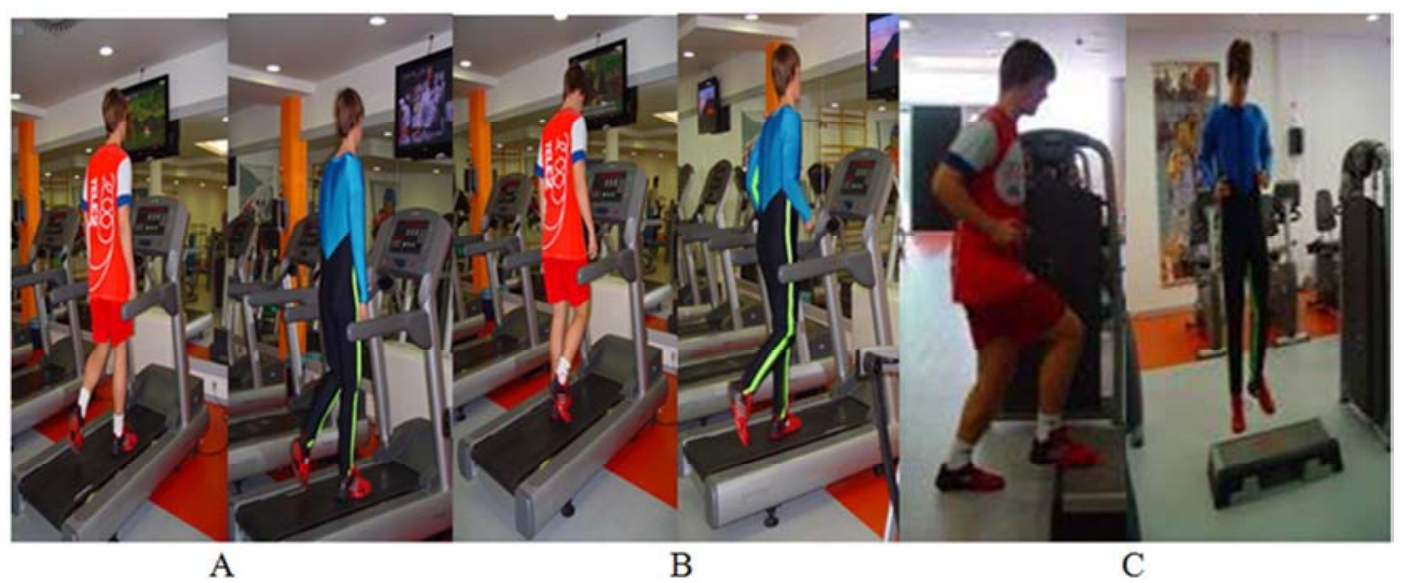

Figure 8. Elements of walking, running and step-ups in sports equipment and in the training process suit.

A. Walking on the treadmill. The intensity of walking is determined by the walking speed (rhythm of $5 \mathrm{~km} / 1$ hour), walking time is limited to $5 \mathrm{~min}$. Obtained results:

1. Walking in sports equipment - the achieved pulse frequency is 118 beats per minute

2. Walking in the training process suit - the achieved pulse frequency is 138 beats per minute.

B. Running on the treadmill. The intensity of running is determined by the running speed (rhythm of $7 \mathrm{~km} / 1$ hour), running time is limited to $5 \mathrm{~min}$. Obtained results:

1. Running in sports equipment - the achieved pulse frequency is 150 beats per minute

2. Running in the training process suit - the achieved pulse frequency is 162 beats per minute.

C. Bench step-ups. The intensity of step-ups is determined by the bench height (bench height is $15 \mathrm{~cm}$ ), step-ups time is limited to $5 \mathrm{~min}$. Obtained results:

1. Step-ups in sports equipment - the achieved pulse frequency is 180 beats per minute

2. Step-ups in the training process suit - the achieved pulse frequency is 220 beats per minute.

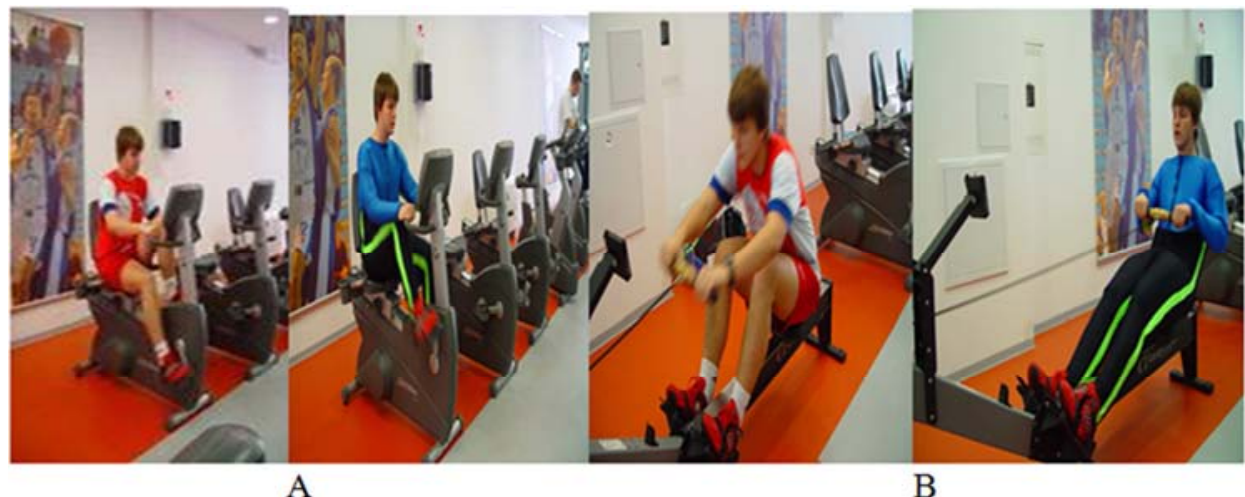

Figure 9. Elements of pedaling on the stationary bicycle and indoor rower, in sports equipment and in the training process suit. 
A. Pedaling on the stationary bicycle. The intensity of pedaling is determined by the load (pedaling on the scale to 6), pedaling time is limited to $5 \mathrm{~min}$. Obtained results:

1. Pedaling in sports equipment - the achieved pulse frequency is 140 beats per minute

2. Pedaling in the training process suit - the achieved pulse frequency is 152 beats per minute.

B. Rowing on indoor rower. The intensity of rowing is determined by the load (rowing on the scale to 8), rowing time is limited to $5 \mathrm{~min}$. Obtained results:

1. Rowing in sports equipment - the achieved pulse frequency is 148 beats per minute

2. Rowing in the training process suit - the achieved pulse frequency is 180 beats per minute.

Application of the suit for activating motor structures in the training process: basketball and volleyball (Figures 10 and 11).

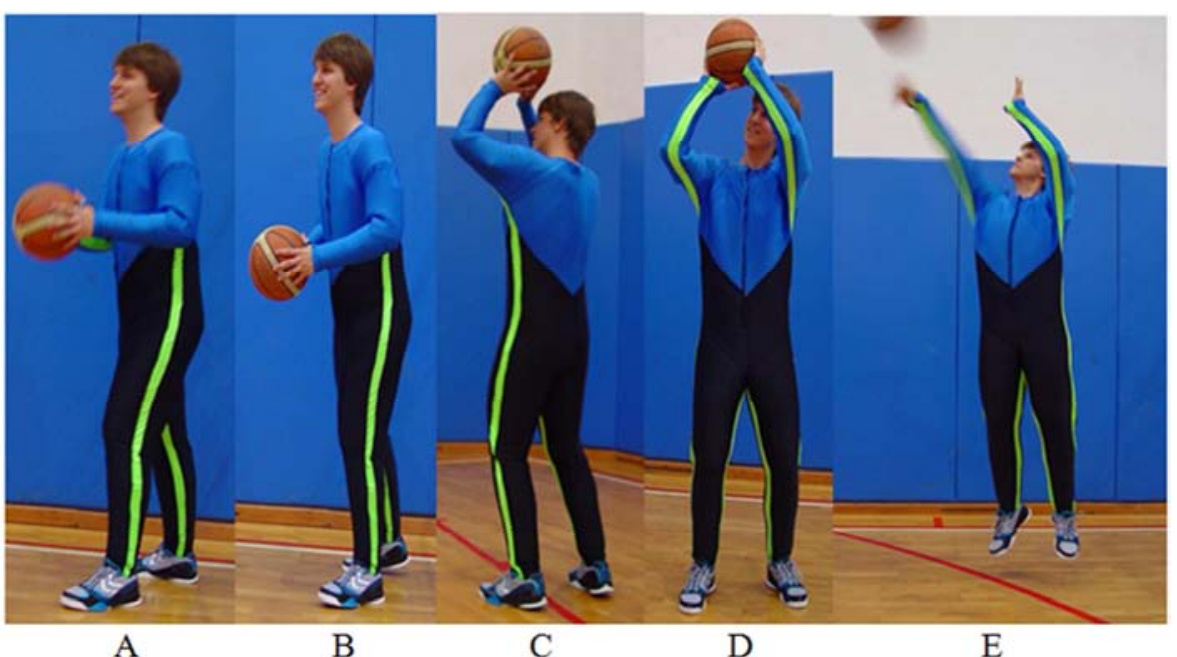

Figure 10. Application of the suit for activating motor structures in the training process of basketball: $A$ - the starting position, $B$ - preparation for throwing, $C$ - taking the position for throwing the ball, D - squat and preparation for jump, E-finish, jump with ball kick.

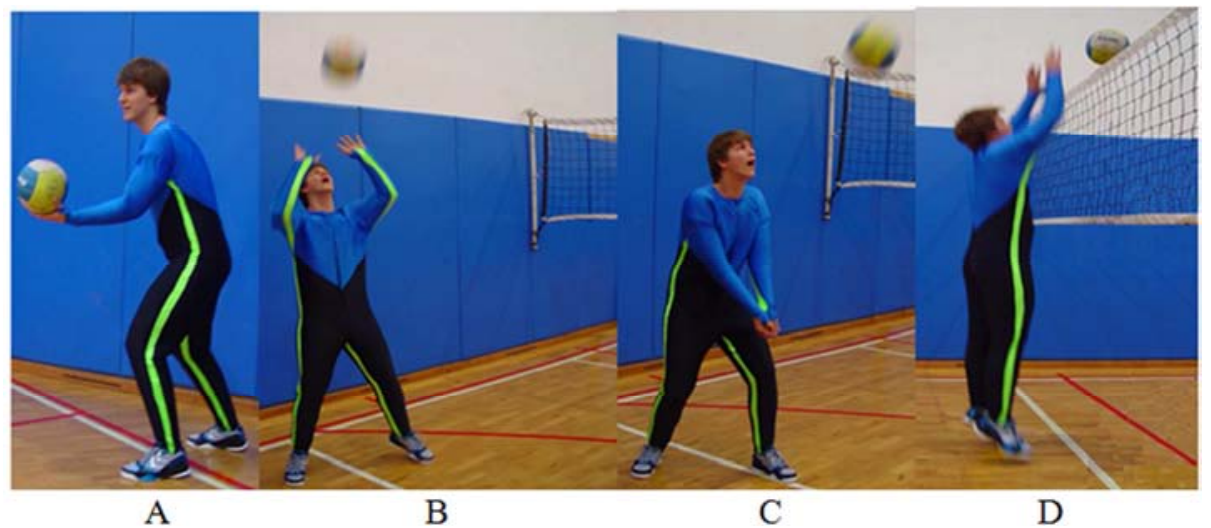

Figure 11. Application of the suit for activating motor structures in the training process of volleyball: $A$ - the starting position for lower serve, $B$ - overhand pass, $C$-forearm pass, $D$ - block jump on the net.

The process of system state monitoring and state transformation, which is reduced to obtaining relevant information about targeted anthropological features in certain time intervals of the workout process application. Time intervals are determined according to the needs of monitoring, evaluating and assessing transformations in the workout process and most often as a part which represents the whole of a unique process it is determined as: the starting state (initial); the central state (transversal); the end state (final).

It is well known that the efficiency of a training session in greatly determined by the selection of intensity and volume and their redistribution in time. In the case of the subject invention, when the training process is carried out in the application of the subject invention, the load selection takes place in the workout process itself. As the load over the suit is distributed proportionally, the intensity of workout is increased, and the load is determined by the type of training and sport. Thus, by creating increased continuous stimuli on the body, significant changes in the explosive, dynamic and static strength, coordination and endurance of the body occur, especially for that activity. In addition, the technical elements of motion (running, shooting, spiking, passing etc.) are performed at an increased intensity, leading to the creation of top motion technique. Therefore, the subject invention has a great efficiency and utility in the development of bodily 
motor and functional abilities and top motion techniques with high achievements in a particular activity. The heart rate monitor "POLAR ACCUREX PLUS" was used in the monitoring process. The results obtained are shown by the load function expressed with the heartbeats derived in the time of performing certain motion (Figure 12).

Practical verification of the subject invention was executed by recording, measuring and testing the applicative values of the suit when walking, running, riding a bicycle simulator, using a rowing simulator and hoping onto a small bench. The aforementioned measurements were taken on the same individuals, with and without the suit of the subject invention. The criteria for measuring were unified for both variations, i.e. using sporting equipment or the suit of the subject invention. Identical movements were executed (walking, running, pedaling, rowing and hoping) under the same conditions (the same application of force and duration

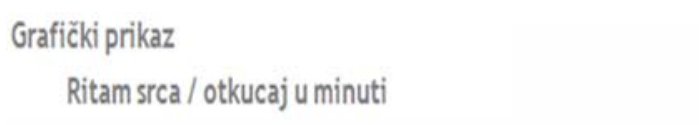

of movement). Based on the results obtained by the measuring instrument "POLAR", heart rates were obtained, which were shown in an analogue format for each movement variation (Figure 12). Lastly, zones expressed in percentages were calculated, which were shown graphically (Figure 13). These values indicate that significantly larger physiological stimuli on the body occurs when using the suit of the subject invention in comparison to using standard sporting equipment for identical movements with the same application of force on a simulator and with the same duration of movement, which partially is the objective of the suit of the subject invention.

On the basis of the graphical representation (Figure 14), it is visible that in all applied motion contents the load intensity is significantly increased, which justifies the basic objective and task of the invention "The Training Process Suit".

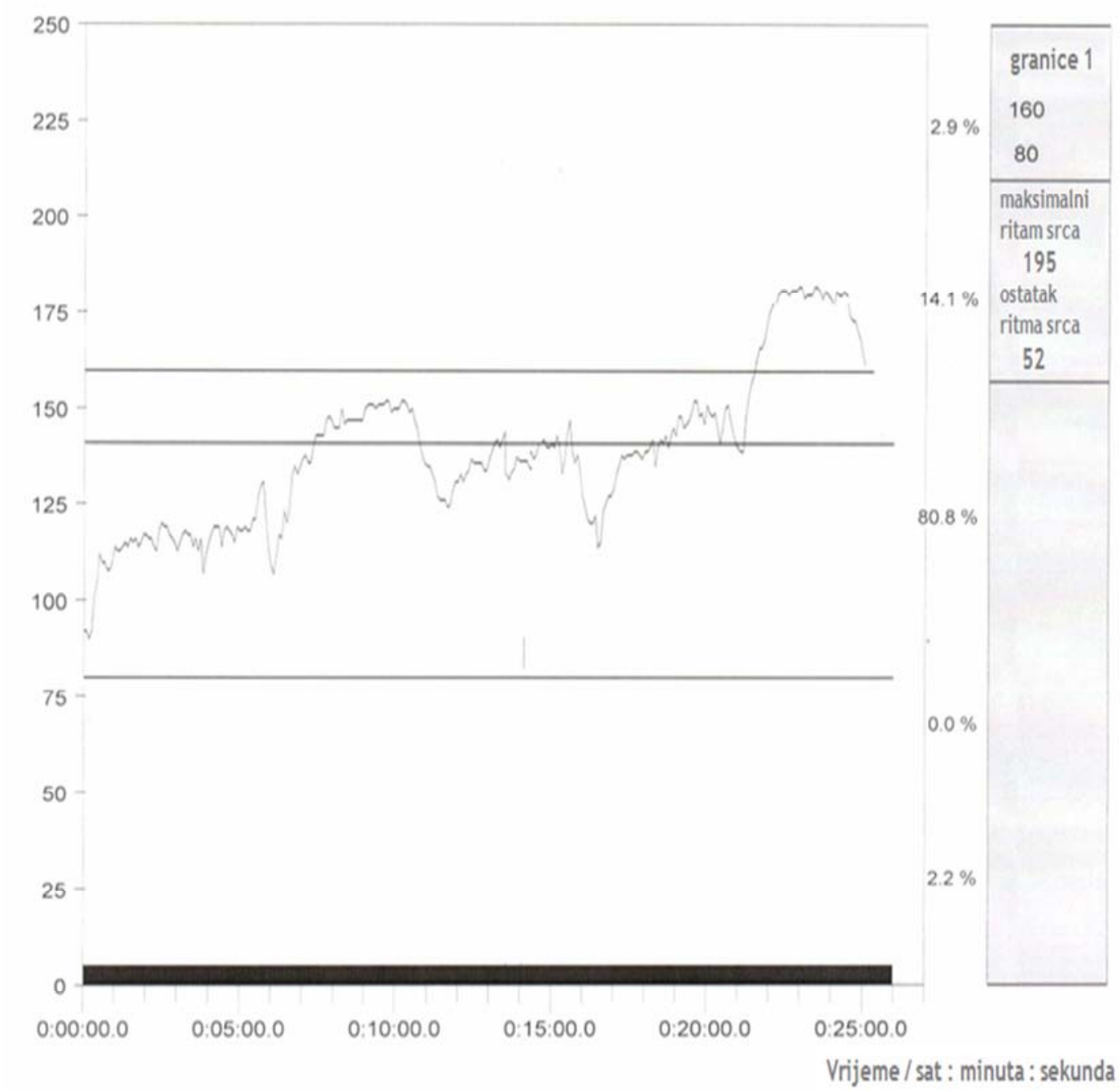


Grafički prikaz

Ritam srca / otkucaj u minuti

Polar Electro Oy $(\subset)$

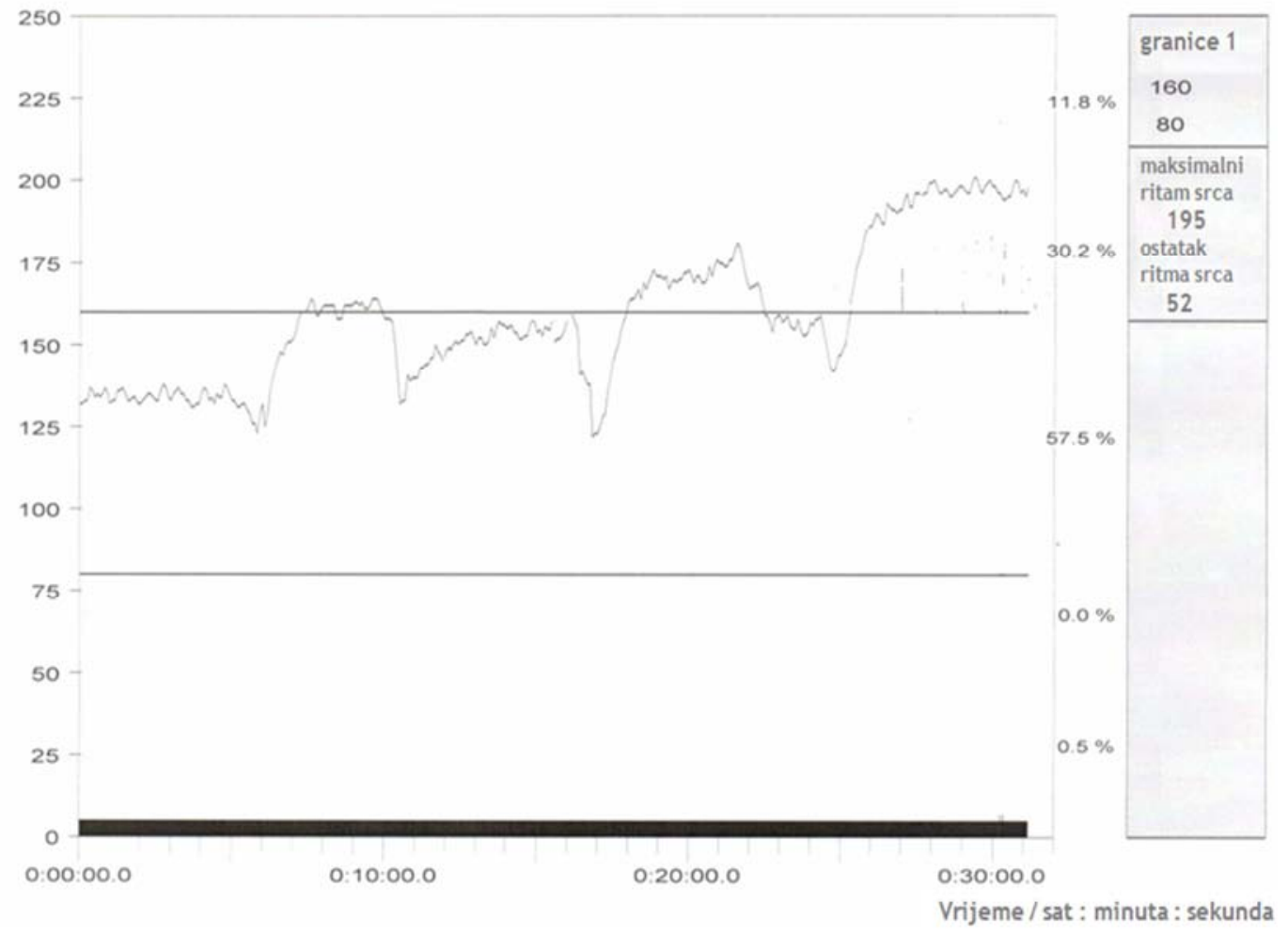

B

Figure 12. Heart frequency: A-motion in sports equipment, $B$ - motion in the training process suit.

\section{Sažetak datoteke}

Postotak vremena (\%)

Granice 1

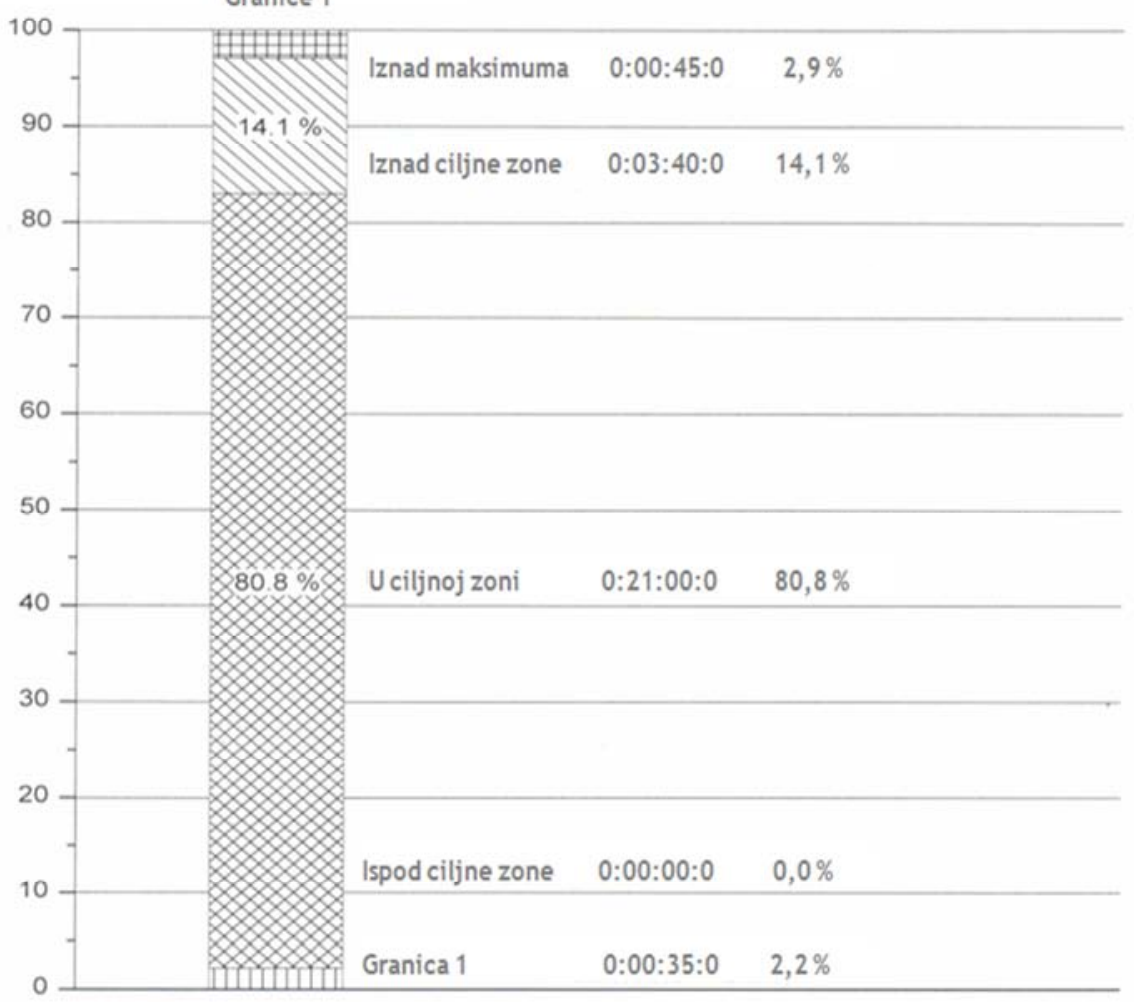

Polar Electro Oy C

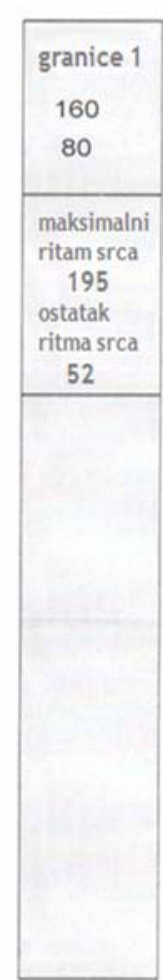




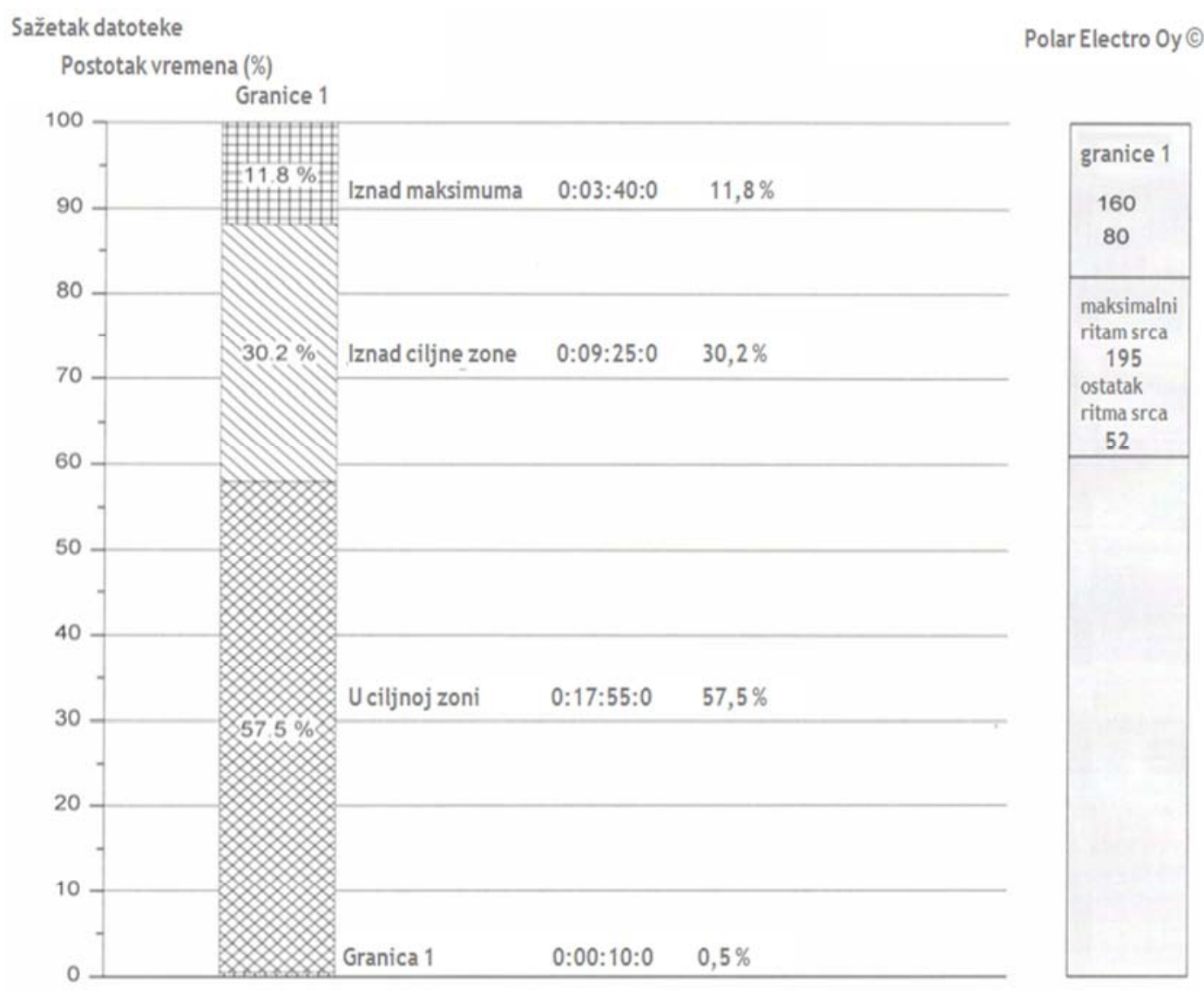

B

Figure 13. Calculated zones expressed in percentages, which are shown graphically, A - motion in sports equipment, B - motion in the training process suit.

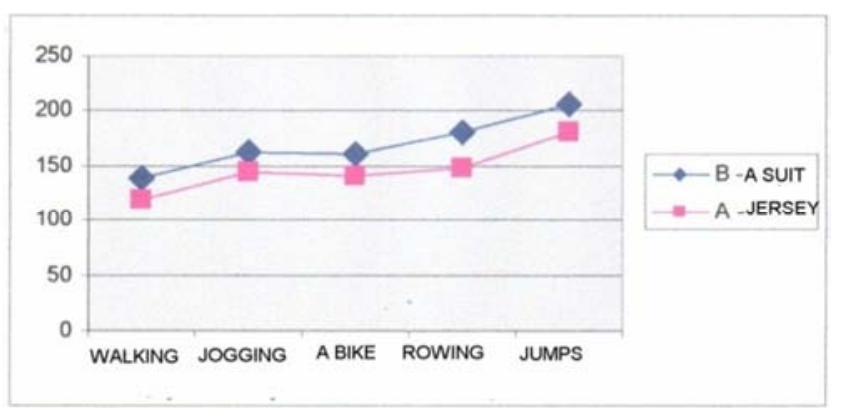

Figure 14. Graphic representation of results obtained in all applied contents; $A$-motion in sports equipment, $B$ - motion in the training process suit.

Thus, with the help of heart rate frequency monitoring, the exact state of the body is shown at the moment of transformation of certain characteristics in the process of performing the motion in sports equipment and in the training process suit. It is clear that there is a significant difference in the intensity of stimuli created by the training process suit, which ultimately leads to greater transformational processes of motor skills and their coordination in the motor structure.

\section{Conclusion}

The dynamic behavior of human motion when proportional body weight has been artificially increased requires knowledge of the distribution of its segmental masses and thus of the dynamic moments of inertia. Anthropometric measurements were used in the study in five percentile groups supplemented by the regression equation of Donski and Zaciorski, which determines the masses of body segments. Based on the anatomical, physiological and biomechanical parameters of the human body, the training process suit is proposed, which basically has biologicalkinetic laws. In the direction of scientific knowledge in this research, the development of mathematical models for distribution of mass and dynamic moments of inertia and of mathematical models for the production of a training process suit was enabled, with the aim of application in sports, physical therapy, recreation and education. In this direction, the development and application of mathematical programs in QBASIC were made to obtain the necessary parameters for the production of the three-layer suit. Based on the physiological and biomechanical parameters, the biomechanical parameters - cyclic and acyclic motion (type of motion) and physiological parameters - aerobic, aerobicanaerobic and anaerobic stimuli were analyzed, and load indexes based on the geometric progression of metabolic processes were determined (aerobic - index 3, aerobicanaerobic - index 6 and anaerobic - index 12). For this purpose, the QBASIC computer program was used to 
calculate the weight gain for individual segments according to load indexes (index $-3,6$ or 12).

The suits model is one-piece, it follows the anatomical morphology with closed ends on the feet and palms, and on the chest there is an opening for putting on and taking off the suit. The suit is made in three layers: the first, base layer is the one that adheres directly to the skin and must have an elasticity factor that will satisfy the required flexibility. Its role is to absorb moisture, for this layer the selected fabric that meets these criteria is elastin. The second, central layer is a layer that provides proportional weight distribution on individual body segments. This layer is made of onecomponent elastic silicone that is cast to the structure of molds of different thicknesses depending on the mass of individual segments (molds are made for individual body parts which have protrusions, canals and ventilation openings). If a model, due to the weight of individual segments, requires greater silicone weight, it is necessary to place lead balls or lead dust in the protrusions in the silicone in order to obtain the required weight so that the silicone remains at the same thickness.

Based on the obtained results using the "POLAR ACCUREX PLUS" measuring instrument, heart rate frequencies were obtained and shown in an analog form for each variant of motion. Finally, zones expressed in percentages were calculated, which are shown graphically. Those values indicate that for the same motion with the same load on the simulator and with the same duration of motion, significantly greater physiological stimuli of the body occur when the training process suit is used compared to the use of standard sports equipment, which was in part the goal of the subject invention.

Finally, the training process suit has enabled the use of new laws to provide a foundation for a new approach to creating new contents, forms and methods in training processes focused on energy transformation aimed at developing skills and achieving top results in education, sports, recreation and physical therapy. The acquired scientific knowledge will serve as a basis for forming the new approach, new models and modeling methods for the training process in which the training process suit is used.

\section{References}

[1] Božić, Ž., Određivanje dinamičkog momenta inercije kod ravninskog skoka u dalj. Zbornik radova «Skup o konstruiranju» Zagreb. F- II - 1- 9. [Determining the Dinamic Moment of Inertia in Areal Long Jump. Collected Papers "Meeting on Development"], 1988.

[2] Clauser, C. E., McConville, J. T., and Young, J. W., "Weight, Volume, and Center of Mass of Segments of the Human Body," AMRL Technical Report (TR-69-70). Wright-Patterson Air Force Base, Ohio, 1969.

[3] CN2865775 (Y) Zhao Huanbin L1 [CN] + Multifunction magnetic therapeutic health weight exercising suit, Publication number: CN2865775 (Y) Publication date: 2007 -02-07. Classification: • international: A61N2/08; A63B 21/065 -
[4] CN2253225 (Y) Liu Jinxia [CN] + Body-building exercising clothes, Publication number: Publicat;on date: 1997 -04-30: Application number: CN19952003075U 19950224 Priority number(s): CN19952003075U 19950224 A63821/065; (IPC 1-7): A63821/065

[5] CN1252316 (A) Zhou Mingliang [CN] + Gravitational training suit, Publication date: 2000-05-10 Classification: international: A63B21/065; (IPC1-?): A63B21/065 • European: Application number: CN19991025095 19991126 priority number(s): CN19991025095 19991126

[6] De Leva, P., “Adjustments to Zatsiorsky-Seluyanov's segment inertia parameters," Journal of Biomechanics, Vol. 29, No. 9, pp. 1223-1230, 1996.

[7] Dodig, M., Biomehanika čovječjeg tijela [Biomechanics of the Human Body] Rijeka: University of Rijeka, 1994.

[8] Dodig, M., Razvoj tjelesnih sposobnosti čovječjeg organizma, Sveučilište u Rijeci. [The Development of Physical Abilities of the Human Organism] University of Rijeka, 1998.

[9] Dodig, M., Modeli i modeliranje tjelovježbenih procesa [Model and Modelling Physical Training Process]. Rijeka: University of Rijeka, 2002.

[10] Dodig, M., Pliometrijski mišićni trening, Sveučilište u Rijeci, [Plyometric muscle training] University of Rijeka, 2002.

[11] Dodig, M., Mehanizmi regulacije gibanja čovječjeg tijela osnove kineziologije [Mechanisms Regulate Motion Human of Body - Basis Kinesiology] University of Rijeka, 2008.

[12] Dodig, M., Relations between Anthropometric Dimensions and Overcome Resistance in Individual Motion. Global Journal of Science Frontier Research (0975-5896) 14, E-2; 27 $32,2014$.

[13] Dodig, M., Relations Between Anthropometric Dimensions and Overcome Resistance in Recurring Motion. American Journal of Educational Research (2327-6126) 2, 6; 393-396, 2014.

[14] Dodig,' M.' (2015).' Canonical' Relations' of Sensorimotor' Reactions' of Multilateral' and' Bilateral' Body' Parts.) Advances) in) Social) Sciences)Research)Journal,)2(5))105B114' Copyright!@! Society! for!Science!and!Education,!United!Kin gdom 105

[15] Dodig, M., Models and Modelling of Dynamic Moments of Inertia of Human Body International Journal of Sports Science 2016, 6(6): 249-256

[16] Dodig, M., Odijelo za trenažni proces, A Suit for the Physical Hysical Training Process, Državni zavod za intelektualno vlasništvo RH. Konsenzualni patent Zagreb, 18. 09. 2015.

[17] Dodig, M., Senzomotoričke reakcije čovječjeg tijela - osnove kineziologije I. [Sensomotor Reactions of the Human Body The Basis of Kinesiology I.] University of Rijeka, PARADOX, d.o.o..Rijeka, 2019.

[18] Donskij, D. D, Zatsiorsky, V. M., Biomehanika. Fiskultura i sport, Moskva. [Biomechanics] Physical training and sports, Moscow, 1979.

[19] Hanavan, E. P., "A Mathematical Model of the Human Body," Technical Report, Aerospace Medical Research Lab., WrightPatterson Air Force Base, OH., 158 pages, 1964. 
[20] Hinrichs, R. N., "Adjustments to the Center of Mass Proportions of Clauser et al. (1969)," Journal of Biomechanics. Vol. 23, No. 9, pp. 949-951, 1990.

[21] Kaleps, O., Clauser, C. E. et al., Investigation into mass distribution properties of the human body and its segments, Ergonomics 27, No 12, 1225-1237., 1984.

[22] Korenev G. B., Wedenie v mehaniku čeloveka, Moskva, Nauka [Introduction čeloveka mechanics] Moscow, Science, 1977.

[23] Muftić, O., Krajina, B., Značaj dinamičke antropometrije u proučavanju sportskih pokreta. Zbornik radova «Skup o konstruiranju», Zagreb. Ergonomija IX 1-9, [Significance of Dynamic Anthropometry in Studying Sports Moves. Collected Papers "Meeting on Development"], 1988.

[24] Radoš, N., Pojednostavljeni dinamički model čovjeka korišten za procjenu traumatskih ozljeda u slabinskom području. Zbornik radova «Skup o konstruiranju», Zagreb, E - XIV - 17. [Simplified Dynamic Model of Man Used for Evaluation of Traumatic Injuries in Flank Area. Collected Papers "Meeting on Development"], 1988.

[25] Rudan, P., Dimenzije tijela i tjelesni položaji pri radu, Medicina rada, Sarajevo, 87-92. [Dimensions of Body and Physical Positions While Working], 1978.

[26] US5937441 (A), Raines Mark T [US] + Weighted exercise and therapeutic suit, US5937441 (A), 1999-08-17, international: A63B21/065; (IPC1-7): A41D13/00 European: A63B21/065 Application number: US1996069242 819960805 Priority number(s): US19960692428 19960805; US19940281490 19940727

[27] US2010319099 (A1), Washington JR Gordon [US]; Fitness \& Training Weight Suite, 2010-12-23, A41D1/00; A63B 21/065 - European: A41D13/00R Application number: US200904B7B5 320090619 Priority number\{s): US200904B7B53 20090619
[28] US005659898A Bell, Jr. Charles Bell, Jr., Exercise Sut Having Flexble Elongated Weights Between Elastic Fabrc Layers Inventor: 3512-A SouthridgeDr., Austin, Tex. 78704 Appl. No.: 324,625 Filed: Oct. 18, 1994.

[29] US2004221355 (A1) Garcia Fernando L [US] + piece full body weighted swimsuit,:ationnumber::ation date: 2004-1111 .

[30] US57687O6, Charles L. Griffith; Antoinette Bacchus Griffith, Midi Weighted Jacket, both of 4316 Saugus Dr., Grand Prairie, Tex. 75052, 11 Patent Number: 5,768,706 (45) Date of Patent: Jun. 23, 1998

[31] Zatsiorsky, V. M., Seluyanov, V. N. and Chugunova, L. G., "Methods of determining massinertial characteristics of human body segments," In Contemporary Problems of Biomechanics, (Ed. Chemyi, G. G. and Regirer, S. A.), CRC Press, MA, pp. 272-291, 1990

[32] W09909846 (A 1) Wilkison William T [US] + Energy Expenditure/Training Garment, Publication number Publication date: 1999-03-04 Inventor(s):+ Classification: Also published as: I US5867826 (A) AU8779698 (A) $\begin{array}{llllllll}\text { EP1017291 (A1) EP1017291 } & \text { (M) "JP2001513581 } & \text { (T) }\end{array}$ international: A41D13/00; A63B21/055; (IPC1-7); A41D13/0-

[33] W00226330 (A 1) Cavallera Pier Giorgio [IT] + Sports Garment For Training, Publication date: 2002-04-04 Classification: -International: A63B21/008; A63B21/055; A63B21/065; (IPC1-7): A63B21/008; A63B21/055; A63B21/065 - European: A63B21/008B4; A63B21/055; A63B21/055D; A63B21/065 Application number: W020001 T00495 20001130 Priority number(s): W020001T00377 20000926

[34] WO2002026330A1, Pier Giorgio Cavallera, Sports garment for training, Priority date, Family: WO (1) Date App/Pub Number Status 2000-11-30 PCT/IT2000/000495 2002-04-04 WO2002026330A1 Application 